IZA DP No. 4630

Produce or Speculate?

Asset Bubbles, Occupational Choice and Efficiency

Pierre Cahuc

Edouard Challe

December 2009 


\title{
Produce or Speculate? Asset Bubbles, Occupational Choice and Efficiency
}

\author{
Pierre Cahuc \\ Ecole Polytechnique, CREST, \\ CEPR and IZA \\ Edouard Challe \\ Ecole Polytechnique, CNRS \\ and Banque de France
}

\section{Discussion Paper No. 4630 \\ December 2009}

\author{
IZA \\ P.O. Box 7240 \\ 53072 Bonn \\ Germany \\ Phone: +49-228-3894-0 \\ Fax: +49-228-3894-180 \\ E-mail: iza@iza.org
}

\begin{abstract}
Any opinions expressed here are those of the author(s) and not those of IZA. Research published in this series may include views on policy, but the institute itself takes no institutional policy positions.

The Institute for the Study of Labor (IZA) in Bonn is a local and virtual international research center and a place of communication between science, politics and business. IZA is an independent nonprofit organization supported by Deutsche Post Foundation. The center is associated with the University of Bonn and offers a stimulating research environment through its international network, workshops and conferences, data service, project support, research visits and doctoral program. IZA engages in (i) original and internationally competitive research in all fields of labor economics, (ii) development of policy concepts, and (iii) dissemination of research results and concepts to the interested public.
\end{abstract}

IZA Discussion Papers often represent preliminary work and are circulated to encourage discussion. Citation of such a paper should account for its provisional character. A revised version may be available directly from the author. 
IZA Discussion Paper No. 4630

December 2009

\section{ABSTRACT \\ Produce or Speculate? Asset Bubbles, Occupational Choice and Efficiency}

We study the macroeconomic effects of rational asset bubbles in an overlapping-generations economy where asset trading requires specialized intermediaries and where agents freely choose between working in the production or in the financial sector. Frictions in the market for deposits create rents in the financial sector that affect workers' choice of occupation. When rents are large, the private gains associated with trading asset bubbles may lead too many workers to become speculators, thereby causing rational bubbles to lose their efficiency properties. Moreover, if speculation can be carried out by skilled labor only, then asset bubbles displace skilled workers away from the productive sector and raise income and consumption inequalities.

JEL Classification: E22, E44, G21

Keywords: rational bubbles, occupational choice, dynamic efficiency

Corresponding author:

Pierre Cahuc

Department of Economics

Ecole Polytechnique

91128 Palaiseau Cedex

France

E-mail: pierre.cahuc@polytechnique.edu 
One of the changes that I would like to see — and I'm going to be talking about in this in weeks to come - is seeing our best and our brightest commit themselves to making things engineers, scientists, innovators. For so long, we have placed at the top of our pinnacle folks who can manipulate numbers and engage in complex financial calculations. And - and that's good. We need some of that. But you know what we can really use is some more scientists and some more engineers who are building and making things that we can export to other countries.

President Barack Obama, Georgetown University Washington, D.C. April 14, 2009

\section{Introduction}

The concern that the financial sector would have been overgrown in recent years, expressed in President Obama's speech, also reflects the view of many professional economists, financial columnists and business leaders. ${ }^{1}$ The prospect of large payoffs from trading complex financial products, the story goes, would ultimately have resulted in a diversion of valuable human resources, notably skilled labor, into financial activities and away from other (and perhaps more efficient) productive and innovative ones. While mostly based on anecdotal evidence, this common assessment of the recent financial history has received some empirical support. For example, Philippon and Reshef (2008) have shown that the U.S. financial sector has attracted much skilled labor in the 1990s and the 2000s, thanks to large income premia relative to the wages paid in other industries. These findings are consistent with those of Goldin and Katz (2008), who document the spectacular ascendancy of finance amongst (male) Harvard graduates over the same period. ${ }^{2}$ Overall, this trend was associated with a pronounced upward movement in the relative size of the financial sector in terms of both GDP and compensation shares -see Philippon (2008), Philippon and Reshef (2008), as well as Figure 1 for a summary of this trend.

This time period coincided with one of exceptionally high asset valuations, first in stock markets in the 1990s, and then in real estate and related structured products in the 2000s. Whilst the issue is probably not completely settled yet, a growing consensus has emerged to argue that the high "DotCom" and other stock prices of the 1990s were due to an asset bubble. ${ }^{3}$ And since the worldwide financial crash of 2007-2008, it is hard to find a contrarian opinion to the view that

\footnotetext{
${ }^{1}$ See, for example, Duflo (2008), Krugman (2009), and Tett (2009), amongst many others.

${ }^{2}$ More specifically, they document that amongst those who graduated in the early 1970 s, about $5 \%$ of them ended up holding a job in the finance industry by the mid-1980s. In constrast, for those who graduated in the early 1990s, $15 \%$ held similar positions in the mid-2000s.

${ }^{3}$ See Ofek and Richardson (2003) and Nagel and Brunnermeier (2004) for the evidence, Shiller (2000) for a behavioral perspective, Pastor and Veronesi (2005) for a contrarian view, and Caballero et al. (2005) for a (rational expectations) model of "speculative growth" with or without asset bubbles applied to the 1990s.
} 

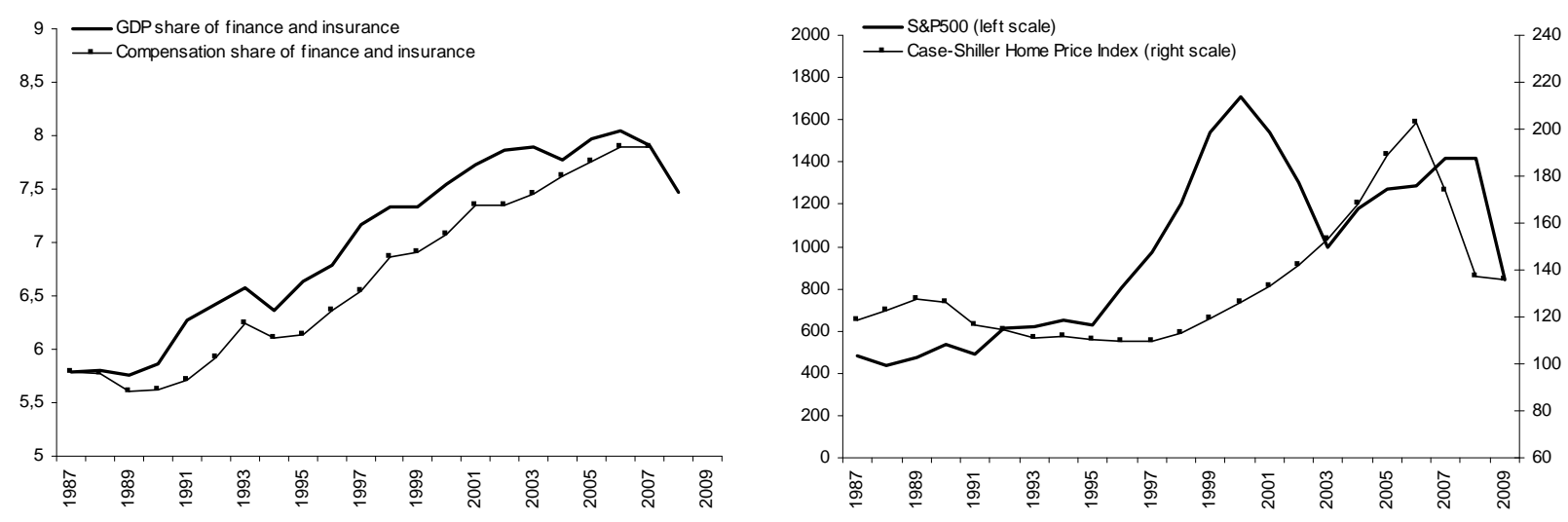

Figure 1: Size of financial sector (Bureau of Economic Analysis, industry accounts) and asset prices (Shiller's dataset) in the U.S.

there was a major asset bubble (perhaps the largest in U.S. financial history) in housing prices and related financial instruments before the crash. ${ }^{4}$ At the time we write, the impact of the crash on the future of the financial sector, and notably on its size, remains uncertain.

The present paper takes the view that these two phenomena -the large and growing size of the financial sector on the one hand, the presence of bubbles in asset markets on the other- are related. We make our point by constructing a consistent general-equilibrium framework in which the interactions between asset bubbles, the size of the financial sector and aggregate efficiency can be studied and disentangled. The starting point of our analysis is a fairly standard overlapping-generations (OLG) model wherein assets can be subject to intergenerational trade at prices higher than their fundamental values, as in Samuelson (1958), Tirole (1985) and Weil (1987). The distinguishing feature of our model is our assumption that firm financing and asset trading require specialized intermediation services. More specifically, our economy has a production as well as a financial sector, and new entrants choose where they wish to work based on the expected payoffs associated with either career. Producers earn the usual wage income, while financiers gather producers' saving, invest them in the menu of available assets, and make a living out of the intermediation margin that they are able to collect. Crucially, we assume that market frictions limit the ability of producers to meet alternative financiers and hence induce rents in the financial sector. These rents in turn affect the relative payoffs associated with financial careers and hence the equilibrium

\footnotetext{
${ }^{4}$ See Blanchard (2009), Brunnermeier (2009), and Greenlaw et al. (2008) for complementary perspectives on the asset-price boom and crisis of the 2000s.
} 
allocation of labor across sectors. ${ }^{5}$ This simple structure delivers the following main results.

First, asset bubbles unambiguously lead to an increase in the size of the financial sector. On the one hand, bubbles raise the returns on traded assets - they generate capital gains on trading bubbles and, by no-arbitrage, also raise the return on other assets like claims to the capital stock. On the other hand, rent extraction by the financial sector implies that speculators pass on to depositors only part of these extra returns, causing the intermediation margin to rise. These greater payoffs make working in finance more attractive and translate into a larger equilibrium size of the financial sector.

Second, the welfare impact of asset bubbles crucially depends on the extent of rent extraction by the financial sector. When financiers have limited market power, they must pass on to depositors much of the extra returns associated with the bubbly equilibrium (relative to the bubbleless equilibrium), enjoy small rents, so that the distortion in the intersectoral allocation of labor remains itself limited. With sufficiently small rents, the beneficial impact of capital crowding out by the bubble is found to remain dominant and the bubbly equilibrium is dynamically efficient (as in Tirole, 1985). On the contrary, large rents induce large inflows of labor into the financial sector in the bubbly equilibrium and substantial distortions in the allocation of labor across sectors. When this crowding out of productive labor by the financial sector is sufficiently severe, asset bubbles lose their efficiency-improving properties and generate potentially large welfare losses for many generations. To summarize, we find that the competing roles of capital crowding out and labor crowding out are key in determining the ultimate impact of bubbles on aggregate welfare, both in the steady state and along the transitional dynamics.

Third, asset bubbles raise income and consumption inequalities. We introduce intra-cohort heterogeneity by dividing the working population into "skilled" and "unskilled" workers. Following Philippon and Reshef's observation that working in a world of highly deregulated and innovative finance requires skills, we assume that the productive sector makes use of both labor types while asset trading can be carried out by skilled labor only. In this context, asset bubbles attract skilled labor into the financial sector and reduce the relative supply of skills in the productive sector. This increases the marginal product of skilled labor while reducing that of unskilled labor, and hence raises the equilibrium wage gap between the two labor types. In particular, we provides plausible examples in which asset bubbles are beneficial to skilled, high-income workers (wherever they work), whilst at the same time being detrimental to unskilled, low-income ones. The relationship between bubbles and income inequalities that is predicted by our model appears consistent with the observed

\footnotetext{
${ }^{5}$ Our consideration of financial sector rents is motivated Philippon and Reshef's (2008) observation that rents accounted for 30 percent to 50 percent of the wage differential between the financial sector and the rest of the private sector in the beginning of the 2000s. While our model has free entry and hence equalization of payoffs in equilibrium, this is the outcome of a process whereby the determinant of rents crucially affect the ultimate size of each sector.
} 
rise in such inequalities in the U.S. during the 1990s and the 2000s (see Autor et al., 2006, Saez, 2009, and Atkinson, Piketty and Saez, 2009).

Our paper is related to at least four strands of research.

First, there is a large (and still growing) literature on the existence, dynamics and efficiency properties of bubbly equilibria (see, for example, Ventura, 2003; Caballero et al., 2006; and Fahri and Tirole, 2009, for recent contributions on this topic). But to the best of our knowledge none of the existing work specifically pertains to the relationship between bubbles and the size of the financial sector. As is well known, in the baseline OLG model of Diamond (1965), where the only friction lies in the demographic structure that prevents agents from participating in all markets, asset bubbles improve welfare (relative to the bubbleless equilibrium) by providing agents with the additional store of values necessary to transfer wealth across periods (see Tirole, 1985, and Weil, 1987, 1989). Asset bubbles can be inefficient, though, when other market imperfections such as capital externalities are added to the OLG structure. For example, Saint-Paul (1992) and Grossman and Yanagawa (1993) show that the crowding out of the capital stock by the bubble loses its efficiency properties under endogenous growth as it lowers growth and the welfare of future generations. Relatedly, Olivier (2000) constructs a model in which households optimally allocate their time endowment between production and research; in this context, bubbles on firms' share favor firm creation and may raise long-run growth. Our paper differs from these three latter studies by ignoring external effects, and is thus closer to the basic (exogenous growth) framework of Diamond, Tirole and Weil. In contrast to Olivier, we focus on the allocation of labor between production and financial intermediation, thereby uncovering a novel source of inefficiency associated with bubbly equilibria.

Second, our paper is related to the contributions of Philippon (2007, 2008), who studies the equilibrium size of the financial sector in a model with endogenous occupational choice in which financiers provide monitoring services to borrowing-constrained entrepreneurs. His framework makes it possible to shed light on a number of interesting issues pertaining to the size of this sector, notably regarding the sources of its historical variations and the desirability of corrective taxes when the decentralized allocation of human capital across sectors is inefficient. However, the impact of asset bubbles on the allocation of labor across sectors has not yet been explored within this framework.

Third, some authors have emphasized the potentially inefficient allocation of talents that may follow from the presence of rents. For example, Baumol (1990) draws on historical evidence to argue that the allocation of entrepreneurial resources in society primarily reflects the distribution of individual, rather than economywide, payoffs and may thus be socially inefficient. In a related contribution, Murphy et al. (1991) construct a model of occupational choice and show how private returns may draw the marginal talent into rent-seeking, with the consequence of slowing down 
economic growth. While these authors explicitly refer to "trading" and "speculation" as prominent rent-seeking activities, they do not specifically study the role of bubbles in attracting talents into the financial sector and the potential drain that may result for other (productive) sectors.

Fourth, there is large literature that sheds light on the interactions between financial market imperfections and macroeconomic activity (see Tirole, 2005, for a survey). Within this strand of research the papers that are most related to our approach are those of Wasmer and Weil (2004), who introduce search frictions in both labor and credit market, as well as Femminis (2002) and Sen (2002), who analyze the effects of rational bubbles when product markets are imperfectly competitive. But none of these papers studies the interactions between asset bubbles, frictions in the market for deposits, and the intersectoral allocation of labor.

Our paper is organized as follows. The basic model is presented in Section 1. Sections 2 and 3 derive the existence and uniqueness of the equilibria of interest, and show that the bubbly equilibrium has a larger financial sector than the bubbleless equilibrium. Section 4 analyzes the efficiency properties of the bubbly equilibrium, and shows that they crucially depend on the size of financial sector rents. Section 5 introduces intra-cohort heterogeneity to study the relationship between asset bubbles and income inequalities. Section 6 provides some concluding comments.

\section{The model}

The economy is populated by overlapping generations of two period-lived, risk-neutral agents who maximize end-of-life consumption. $N_{t}$ agents are born at date $t$, and the population grows at rate $n \geq 0$. Every agent is endowed with one unit of labor when young. A newly born agent chooses between working in the production sector or entering the financial sector, and we denote by $L_{t}$ the number of "workers" in the population at date $t$ (so that $N_{t}-L_{t}$ is the number of "financiers" in the population). The central difference between workers and financiers is in the technologies that they have access to. There are two goods: labor, and a numeraire good, which is produced, invested and consumed.

\section{$1.1 \quad$ Technologies}

The numeraire good is produced with a constant returns to scale technology, $F\left(K_{t}, L_{t}\right)$, which is concave, increasing with respect to the quantity of capital, denoted by $K_{t}$, and of labor, denoted by $L_{t} . F\left(K_{t}, L_{t}\right)$ satisfies Inada conditions. All agents have access to a storage technology that yields $\lambda>0$ units of the numeraire good at date $t+1$ for 1 unit stored at date $t$. Only financiers, who are specialized intermediaries, can successfully lend to firms (think of them, for example, as having devoted their first-period labor endowment to the acquisition of unique monitoring and 
asset management skills).

Agents enjoy late-life consumption only. Agents working in the production sector get the wage $w_{t}$ in early life. Financiers get no wage in early life, but make a living out of the intermediation margin they extract by borrowing from lenders and lending to firms. Hence, workers provide for late-life consumption either by storing their wage or by lending it to financiers.

Capital depreciates at rate $\delta \in[0,1]$. We denote by $k_{t}=K_{t} / N_{t}$ the amount of capital per worker and by $\ell_{t} \equiv L_{t} / N_{t}$ the share of the working population engaged in the productive sector (i.e., $1-\ell_{t}$ is the size of the financial sector). With $f\left(k_{t} / \ell_{t}\right)=F\left(K_{t}, L_{t}\right) / L_{t}$ denoting the production function in intensive form, profit maximization by the firm yields:

$$
\begin{gathered}
w_{t}=f\left(k_{t} / \ell_{t}\right)-\left(k_{t} / \ell_{t}\right) f^{\prime}\left(k_{t} / \ell_{t}\right) \equiv \omega\left(k_{t} / \ell_{t}\right), \\
r_{t}+\delta=f^{\prime}\left(k_{t} / \ell_{t}\right)
\end{gathered}
$$

In what follows we refer to $1+r_{t}$ as the (gross) "productive" rate, as opposed to the "interest rate" that financiers promise to workers, which we denote by $1+\rho_{t}$. Henceforth we will focus on the non trivial case where the gross productive rate is strictly larger than the returns on the storage technology (the conditions ensuring that this will indeed be the case in equilibrium are given below.)

\subsection{Labor allocation}

Agents choose their occupation (or sector) according to the terminal consumption that they expect from working in either sector. Occupation choice is made at the beginning of life. It is irreversible. In equilibrium, free entry in both sectors will ensure that expected payoffs are equalized and will determine the equilibrium size of each sector. We assume that there are market frictions in the financial sector, which allow financiers to earn a positive unit intermediation margin and thus find this occupation worthwhile.

\subsubsection{The financial sector}

After workers have decided to engage in the production sector, they start looking for a financier to whom they will lend their wage income at the end of the period. Producers are randomly matched with financiers according to a standard "urn-ball" model (e.g., Hall, 1977) whereby a particular worker meets any active financier with equal probability, $1 /\left(N_{t}-L_{t}\right)$, while financiers can be matched with as many workers as they happen to meet. ${ }^{6}$ After the match has taken place,

\footnotetext{
${ }^{6}$ In this framework, a worker is matched with (at most) one financier at any point in time, while the ex-post numbers of financiers' customers is a Poisson distributed random variable with parameter $\ell_{t} /\left(1-\ell_{t}\right)$. Indeed, the probability that a financier is matched with any particular worker is $1 /\left(N_{t}-L_{t}\right)$. Then, the probability that a financier
} 
the worker and the financier bargain over the joint surplus to be earned from the relationship, and we denote by $\tilde{\theta} \in(0,1)$ the share of the surplus that accrues to a financier in a particular match. Importantly, the monopolistic power of the financier at this stage is limited by the fact that workers can decline the deal and restart searching for a financier (with the same random matching process); however, for time constraints they can only search for a finite number of times $\tau \geq 1$. We show in Appendix A1 that the outcome of this random matching and bargaining process is the following: i) workers strike a deal with the first financier that they meet; ii) the interest rate on which they agree to deal is:

$$
1+\rho_{t+1}=\theta \lambda+(1-\theta)\left(1+r_{t+1}\right)
$$

where $\theta \equiv \tilde{\theta}^{\tau} \in(0,1)$. In the remainder of the paper we shall refer to the composite parameter $\theta$ as the market power of financiers. This market power can be high (low) either because their

bargaining power in a particular match, $\tilde{\theta}$, is high (low), and/or because lenders' ability to meet alternative trading partners, as measured by $\tau$, is high (low).

Equation (3) expresses the interest rate as a weighted sum of the returns on the two underlying technologies, storage and production. When financiers enjoy much market power, they are able to keep the interest rate accruing to workers close to the relatively low storage return (that is, the ultimate outside option for workers). On the contrary, when financiers have little market power their rent is limited and the interest rate must remain close to the relatively high productive rate.

It is convenient to rewrite (3) in terms of the intermediation margin that financiers are able to extract from their matches with workers:

$$
r_{t+1}-\rho_{t+1}=\theta\left(1+r_{t+1}-\lambda\right)
$$

In equation (4), the return difference $1+r_{t+1}-\lambda$ is the economywide surplus, per unit of savings, from investing in the production sector rather than storing. Then, the intermediation margin $r_{t+1}-\rho_{t+1}$ is the fraction of this unit surplus that accrues to financiers.

\subsubsection{Occupational choice}

Agents born at date $t$ must choose at beginning of date $t$ whether to become a worker or a financier, on the basis of the expected date $t+1$ consumption from either occupation. The terminal be matched with $b$ (out of $L_{t}$ ) workers is:

$$
\left(\begin{array}{c}
b \\
1 /\left(N_{t}-L_{t}\right)
\end{array}\right)\left(\frac{1}{N_{t}-L_{t}}\right)^{b}\left(1-\frac{1}{N_{t}-L_{t}}\right)^{L_{t}-b} .
$$

This binomial distribution converges towards the Poisson distribution with parameter $L_{t} /\left(N_{t}-L_{t}\right)=\ell_{t} /\left(1-\ell_{t}\right)$ when $L_{t}$ and $N_{t}-L_{t}$ are sufficiently large. Hence, the probability that a financier is mached with $b$ workers is $e^{-\ell_{t} /\left(1-\ell_{t}\right)}\left(\ell_{t} /\left(1-\ell_{t}\right)\right)^{b} /(b !)$. 
consumption of a worker born at date $t$ who lends his savings to financiers is:

$$
c_{t+1}=w_{t}\left(1+\rho_{t+1}\right)
$$

Let us now turn to financiers. Their payoff from any match is $w_{t}\left(r_{t+1}-\rho_{t+1}\right)$. Since they are in number $N_{t}-L_{t}$ while workers are in number $L_{t}$, and given the assumed matching process, the expected number of matches for a potential financier is $\ell_{t} /\left(1-\ell_{t}\right)$. Hence the total expected consumption from choosing a career in finance is:

$$
\mathbb{E}_{t}\left(c_{t+1}^{f}\right)=\frac{\ell_{t} w_{t}}{1-\ell_{t}}\left(r_{t+1}-\rho_{t+1}\right) .
$$

Note that (6) is the expected consumption of an agent considering to become a financier, while the actual (ex post) consumption level of a particular financier depends on his random realized number of matches.

The equilibrium allocation of labor across sectors is determined by free entry. Since agents are risk-neutral, they must get the same expected consumption from either occupation, so that we must have $\mathbb{E}_{t}\left(c_{t+1}^{f}\right)=c_{t+1}$. In what follows we may thus refer to $c_{t+1}$ as "individual consumption", defined as aggregate consumption divided by the number of old agent at date $t+1$, i.e., $N_{t+1}$. Equating (5) and (6) and using (4), we find that the equilibrium share of the financial sector is:

$$
1-\ell_{t}=\theta\left(1-\frac{\lambda}{1+r_{t+1}}\right)
$$

which is positive provided that gross productive rate, $1+r_{t+1}$, is larger than the storage return, $\lambda$.

The interpretation of equation (7) is straightforward: when the market power of financier, $\theta$, is small, then so is the intermediation margin they are able to extract (see equation (4)) and thus the attractiveness of the financial sector. If, on the contrary, $\theta$ is large (i.e., financiers have strong market power), then the large implied margin attracts many agents into the financial sector $e x$ ante and hence the number of workers in the production sector is small. A version of the basic overlapping generations model of Diamond (1965) and Tirole (1985) is recovered as a particular case of our framework when we set $\theta=0$, in which case $\ell_{t}=1$ for all $t$. At the extreme opposite, the crowding out of human resources by the financial sector is maximum when $\theta=1$, in which case $\ell_{t}=\lambda /\left(1+r_{t+1}\right)$. Similarly, changes in lenders' outside option, $\lambda$, alter the rent that financiers can extract and thus the equilibrium size of the financial sector.

The effect of the productive rate, $1+r_{t+1}$, on labor allocation across sectors also has a straightforward interpretation. Financiers extract a rent from their exclusive access to firms' financing. When the productive rate increases, matched financiers are able to extract some of the additional payoff and hence the intermediation margin rises. This in turns raises the expected payoff from working in the financial sector and reduces the share of producers in the population. Unsurprisingly, 
this effect is scaled by the market power of financiers, as well as by producers' outside investment opportunities, since they both determine how much of the extra surplus financiers can extract from an increase in the productive rate. Finally, note that the labor allocation equation (7) implies that the size of the financial sector shrinks to zero as market frictions vanish. This is because in our baseline specification financiers can handle an arbitrarily large number of customers once their career choice is made and their access to asset markets is granted. Then, by no-arbitrage between alternative career choices, a lower unit intermediation margin, $r_{t+1}-\rho_{t+1}$, induced by a small value of $\theta$ must be offset by an increase in the number of customers that any single financier can expect. In the limit the intermediation margin shrinks to zero as $\theta \rightarrow 0$ and a single financier, with measure zero, manages all producers savings.

It should be noticed that the assumption that the (frictionless) optimal size of the financial sector is zero is not an essential feature of our model. Appendix A2 studies an alternative specification of the model wherein financiers have limited capacity and hence the number of customers that any single financier can handle is bounded above (this may be viewed as a particular example of increasing marginal cost to intermediation, where this cost becomes very large when the number of clients exceeds some upper limit). In this situation, the optimal size of the financial sector is bounded away from zero and whether market frictions make it too big or not, relative to the first best, depends on the value of $\theta$, the market power of financier

\section{Bubbleless equilibrium}

\subsection{Aggregate dynamics and steady state}

In the bubbleless equilibrium workers' savings transit through financiers' hands and are then entirely turned into productive capital. Since workers save their entire wage income, the law of motion for capital is $K_{t+1}=w_{t} L_{t}$, which we may rewrite as:

$$
(1+n) k_{t+1}=\ell_{t} \omega\left(k_{t} / \ell_{t}\right)
$$

On the other hand, equations (2) and (7) relate current occupational choices to the productive rate, and hence to the stock of capital per producer in the next period:

$$
\ell_{t}=1-\theta+\frac{\theta \lambda}{f^{\prime}\left(k_{t+1} / \ell_{t+1}\right)+1-\delta}
$$

Equations (8) and (9) define, together with the initial value of capital, $k_{0}$, the equilibrium path of $\left(k_{t}, \ell_{t}\right)$. It should be noticed that in contrast to capital, the share of financiers is forward-looking because current occupational choices depend on anticipated payoffs and hence on the interest rate that will prevail in the next period. In equation $(9), \ell_{t}$ is increasing in $k_{t+1} / \ell_{t+1}$ since a high value 
of the latter ratio is associated with a low productive rate, which deters agents from working in the financial sector and thus raises the size of the productive sector. Note also that in the particular case where $\theta=0$, equation (9) yields $\ell_{t}=1$ and hence from (8) the path of $k_{t}$ is described by the univariate (Diamond-like) dynamics $k_{t+1}=\omega\left(k_{t}\right) /(1+n)$. When $\theta>0$, on the contrary, the stock of capital and the allocation of labor across sectors are jointly determined according to (8)-(9).

Let us denote by $k^{*}$ and $\ell^{*}$ the steady state values of capital per worker and the size of the production sector, respectively, in the bubbleless equilibrium. From (8)-(9) we get:

$$
\ell^{*}=1-\theta+\frac{\theta \lambda}{f^{\prime}\left(\gamma^{-1}(1+n)\right)+1-\delta}, k^{*}=\gamma^{-1}(1+n) \ell^{*},
$$

where $\gamma(k / \ell) \equiv \omega(k / \ell) /(k / \ell)$. We now make the following assumptions:

$$
\begin{gathered}
\gamma^{\prime}(.)<0, \gamma(0)=+\infty, \gamma(+\infty)=0 \\
f^{\prime}\left(\gamma^{-1}(1+n)\right)+1-\delta>\lambda .
\end{gathered}
$$

Assumption (A1) ensures that the steady state defined by (10) exists and is unique. (A2) guarantees that in the bubbleless steady state the value of the productive rate (left hand side) is always greater than the storage return (right hand side); this will imply that in the vicinity of that steady state there will always be a range of interest rates, $\rho_{t}$, allowing financiers to extract a positive intermediation margin (i.e., $r_{t+1}-\rho_{t+1}>0$ ) while still be able to attract lenders' deposits (i.e., $\left.\rho_{t+1}>\lambda\right) .^{7}$

Note from (10) that output per worker in the bubbleless steady state, $Y / N$, is $y^{*}=\ell^{*} f\left(k^{*} / \ell^{*}\right)=$ $\ell^{*} f\left(\gamma^{-1}(1+n)\right)$. Since under assumption (A2) the share of the population engaged in production, $\ell^{*}$, decreases with the market power of financiers, $\theta$, higher values of $\theta$ reduce output per worker. Finally, from (5) and (10) individual consumption in the bubbleless steady state is given by:

$$
c^{*}(\theta)=\omega\left(\gamma^{-1}(1+n)\right)\left[\theta \lambda+(1-\theta)\left(f^{\prime}\left(\gamma^{-1}(1+n)\right)+1-\delta\right)\right]
$$

and thus decreases with $\theta$, the market power of financiers.

\subsection{Stability and local dynamics}

We focus on the behavior of the dynamic system in the vicinity of the steady state $\left(k^{*}, \ell^{*}\right)$. Loglinearizing (8)-(9) around $\left(k^{*}, \ell^{*}\right)$ generates a two-dimensional linear system, the stability of which depends on the number of characteristic roots inside the unit circle and the number of predetermined variables in the system (Blanchard and Kahn, 1980). We show in Appendix B1 that the characteristic polynomial summarizing the local dynamics of the bubbleless equilibrium has either

\footnotetext{
${ }^{7}$ If this condition were not fulfilled the equilibrium share of financiers would go to zero and the value of $k_{t}$ would be constant and given by $f^{\prime}\left(k_{t}\right)+1-\delta=\lambda$.
} 
one or two roots inside the unit circle. Since the system has one predetermined variable $\left(k_{t}\right)$ and one free variable $\left(\ell_{t}\right)$, this implies that either there is a unique equilibrium trajectory converging towards $\left(k^{*}, \ell^{*}\right)$ and indexed by $k_{0}$ (determinacy), or this equilibrium is surrounded by an infinity of equilibrium trajectories converging towards $\left(k^{*}, \ell^{*}\right)$ and indexed by $\left(k_{0}, \ell_{0}\right)$ (indeterminacy). More precisely, we find that the bubbleless steady state is determinate if and only if:

$$
\frac{1+\alpha^{*}}{\epsilon^{*}}\left[1+\left(\frac{1-\theta}{\theta}\right) \frac{f^{\prime}\left(\gamma^{-1}(1+n)\right)+1-\delta}{\lambda}\right]>2,
$$

where $\alpha^{*} \in(0,1)$ and $\epsilon^{*}>0$ denote the elasticity of the real wage and (minus) that of the productive rate with respect to capital, respectively, evaluated at the bubbleless steady state:

$$
\alpha^{*}=\frac{\left(k^{*} / \ell^{*}\right) \omega^{\prime}\left(k^{*} / \ell^{*}\right)}{\omega\left(k^{*} / \ell^{*}\right)}, \epsilon^{*} \equiv-\frac{\left(k^{*} / \ell^{*}\right) f^{\prime \prime}\left(k^{*} / \ell^{*}\right)}{f^{\prime}\left(k^{*} / \ell^{*}\right)+1-\delta} .
$$

Condition (12) is not strong. For example, it is satisfied for all feasible values of the other parameters in the Cobb-Douglas case, where $y=k^{\alpha}$ and hence $\alpha^{*}=\alpha$, as long as $\alpha \geq 1 / 3$. It is also satisfied for any value of $\alpha$ when $\theta \leq 1 / 2$. In any case, it is satisfied provided that the return on storage, $\lambda$, lies sufficiently below the steady state gross productive return $f^{\prime}\left(\gamma^{-1}(1+n)\right)+1-\delta$. In the remainder of the paper we shall work out the dynamics of the model for the case where condition (12) is satisfied, so that $k_{0}$ uniquely pins down $\ell_{0}$ and sets the economy on the unique equilibrium trajectory converging towards $\left(k^{*}, \ell^{*}\right)$. However, since our results on the welfare impact of rational bubbles follow from the asymptotic properties of the bubbly equilibrium and that indeterminacy also implies convergence towards the steady state, this focus is for expositional clarity and should not be seen as essential in our analysis.

Under condition (12) the local dynamics of $k_{t}$ in the bubbleless equilibrium is governed by the unique stable root of the system, denoted by $p_{1}$, and we have (see Appendix B for details):

$$
k_{t}=\left(1-p_{1}\right) k^{*}+p_{1} k_{t-1}, p_{1} \in(0,1)
$$

This dynamics is represented in Figure 2. Given $k_{t}$, equation (14) uniquely determines $k_{t+1}$.

\section{Bubbly equilibrium}

\subsection{Dynamics and steady state}

We now derive the bubbly equilibrium of our economy and compare it to the bubbleless equilibrium. We assume that bubbles, like claims to the capital stock, can only be traded by financiers. Hence, in the bubbly equilibrium financiers who enter the market buy bubbly assets from those who leave the market against the numeraire good that they have borrowed from young producers. In their second period of life, financiers resell the bubble to the next cohort of financiers and then clear their 


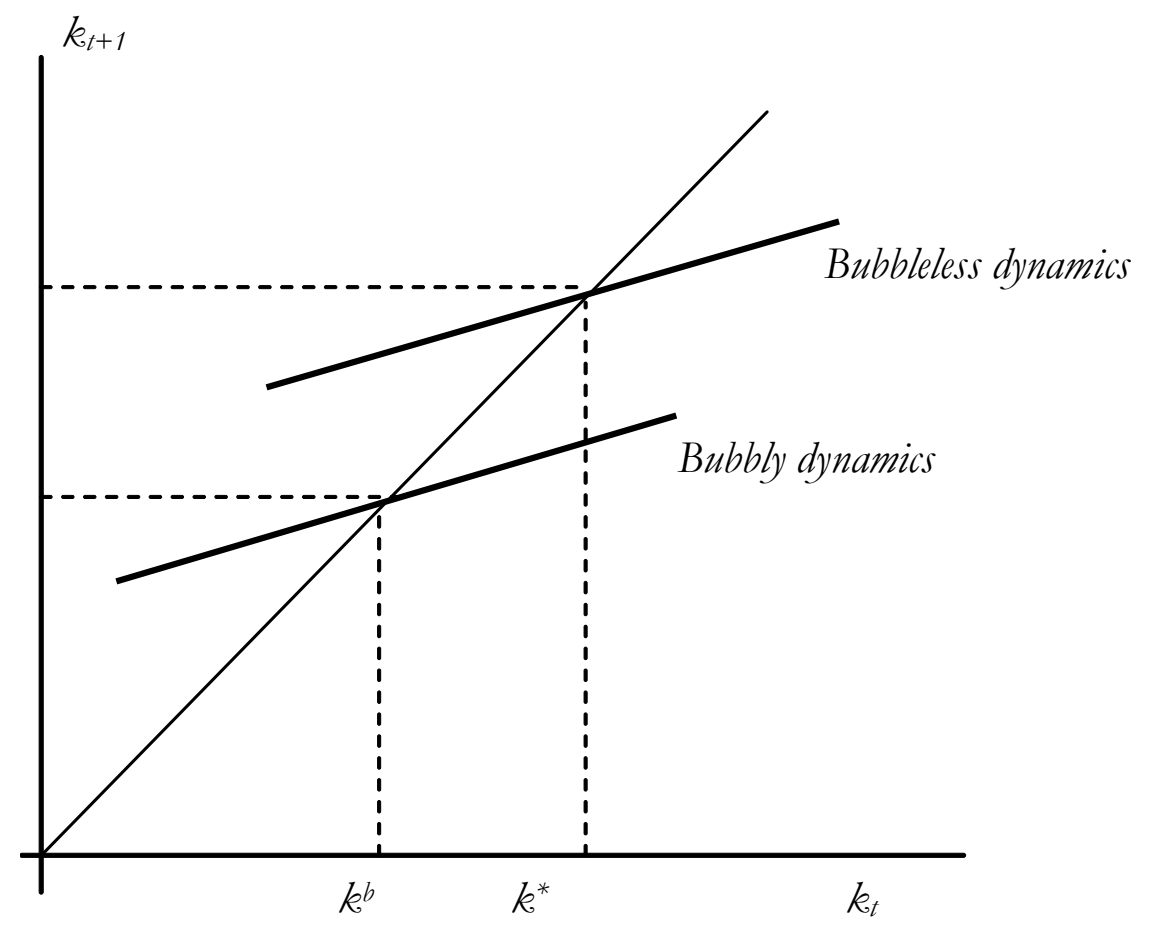

Figure 2: Bubbly and bubbleless equilibria

balance with producers. This implies that financiers' intermediation margin now includes some of the capital gains earned by "riding the bubble".

For expositional clarity we focus on "pure" bubbles with no underlying real asset, but it would be straightforward to introduce a tree with constant payoff and to interpret the bubble as the difference between the trading price of this tree and its fundamental value (as in Tirole, 1985). Moreover, we only study equilibria that are "asymptotically bubbly", that is, equilibria in which the bubble per worker has strictly positive steady state value. We make specific assumptions below ensuring the existence of such equilibrium paths, along which the bubble per worker does not vanish asymptotically.

In the bubbly equilibrium, total savings are invested in the production technology as well as in the bubble, i.e., $B_{t}+K_{t+1}=w_{t} L_{t}$. Denoting by $b_{t}=B_{t} / N_{t}$ the value of the bubble per worker at the end of date $t$, we have:

$$
b_{t}+(1+n) k_{t+1}=\ell_{t} \omega\left(k_{t} / \ell_{t}\right)
$$

On the other hand, the absence of arbitrage opportunities requires that from the point of view of financiers the return on trading the bubble be equal to that on investing in the production 
technology, i.e., $B_{t+1}=\left(1+r_{t+1}\right) B_{t}$. From (2), we must thus have:

$$
b_{t+1}=\left(\frac{f^{\prime}\left(k_{t+1} / \ell_{t+1}\right)+1-\delta}{1+n}\right) b_{t}
$$

Along an asymptotically bubbly equilibrium the steady state value of the bubble per worker is constant and positive, implying that the ratio in (16) is equal to one. From (7) and (15)-(16) and the properties of $f($.$) , the bubbly steady state \left(k^{b}, \ell^{b}, b\right)$ is unique and given by:

$$
\ell^{b}=1-\theta+\frac{\theta \lambda}{1+n}, \quad k^{b}=f^{\prime-1}(n+\delta) \ell^{b}, \quad b=\ell^{b}\left[\omega\left(\frac{k^{b}}{\ell^{b}}\right)-\frac{(1+n) k^{b}}{\ell^{b}}\right] .
$$

The necessary and sufficient condition for the existence of an equilibrium with asymptotically positive asset bubble is $\omega\left(k^{b} / \ell^{b}\right) /\left(k^{b} / \ell^{b}\right)=\gamma\left(k^{b} / \ell^{b}\right)>1+n$. Since $\gamma^{\prime}()<$.0 (from Assumption (A1)) and $1+n=\gamma\left(k^{*} / \ell^{*}\right)$ (see (10)), steady state bubbles exist if and only if $k^{b} / \ell^{b}<k^{*} / \ell^{*}$, i.e., if and only if the bubble asymptotically crowds out capital per worker in the productive sector. Equivalently, steady state bubbles are possible if and only if the real interest rate is higher in the bubbly steady state than in the bubbleless one, i.e., $f^{\prime}\left(k^{b} / \ell^{b}\right)=n+\delta>f^{\prime}\left(k^{*} / \ell^{*}\right)=\gamma^{-1}(1+n)$. Hence we can make sure that asymptotically bubbly equilibria exist by assuming that the following condition holds:

$$
n+\delta<f^{\prime}\left(\gamma^{-1}(1+n)\right)
$$

For example, if the production function is $f(k)=k^{\alpha}$, this condition boils down to $n+\delta>$ $\alpha(1+n) /(1-\alpha)$.

Note first that even though the existence of a steady state with positive bubble is related to the production technology, the population growth rate and the rate of depreciation, it does not depend on the market power of financiers. However, the size of the bubble per worker depends on $\ell^{b}$ and thus on $\theta$. Second, the higher productive rate that prevails in the bubbly steady state (relative to that in the bubbleless steady state) is associated with a more attractive financial sector and hence a smaller size of the production sector, i.e., $\ell^{b}<\ell^{*}$. Finally, since $k^{b} / \ell^{b}<k^{*} / \ell^{*}$ while $\ell^{b}<\ell^{*}$, it follows that $k^{b}<k^{*}$, i.e., the bubble crowds out capital per worker. We summarize these results in the following proposition.

Proposition 1. For all feasible values of $\theta$ the bubbly steady state has lower capital per worker, $k$, greater productive rate, $f^{\prime}(k / \ell)+1-\delta$, and a larger financial sector, $1-\ell$, than the bubbleless steady state.

The impact of general equilibrium asset bubbles on the capital stock and the rental rate in the long run are well known since the work of Tirole (1985) and Weil (1987). The novelty here is that differences in capital per worker between the bubbly and the bubbleless equilibria affect occupational choices (through their impact on the productive rate) and thus the allocation of labor 
across sectors. In short, bubbles crowd out productive labor, in addition to crowding out productive capital. Finally, from (5) and (17) individual consumption in the bubbly steady state is given by:

$$
c^{b}(\theta)=\omega\left(f^{\prime-1}(n+\delta)\right)[\theta \lambda+(1-\theta)(1+n)]
$$

and hence decreases with the market power of financiers, $\theta$.

\subsection{Stability and local dynamics}

We proceed as in Section 2.2 and derive the dynamics of the system in the vicinity of the bubbly steady state. Moreover, since we wish to compare equilibrium trajectories that, for a particular level of initial capital $k_{0}$, may converge towards either the bubbleless steady state or the bubbly steady state, we assume that the two steady states under scrutiny lie in the vicinity of each other. ${ }^{8}$ We can then show (see Appendix $\mathrm{C}$ for details) that the steady state $\left(k^{b}, \ell^{b}, b\right)$ is determinate provided that condition (12) is satisfied, implying that the bubbly equilibrium $\left(k_{t}, \ell_{t}, b_{t}\right)$ is locally unique.

As is shown in Appendix C, around the bubbly steady state the dynamics of the capital stock can be first-order approximated as follows:

$$
k_{t}=\left(1-\tilde{p}_{1}\right) k^{b}+\tilde{p}_{1} k_{t-1}, \tilde{p}_{1} \in(0,1)
$$

where $\tilde{p}_{1}$ is the (unique) stable root of the bubbly system (see Figure 1 again). Since $k^{b}<k^{*}$, the dynamics of $k_{t}$ along the bubbly equilibrium crosses the 45-degree line below that of the bubbleless equilibrium. Moreover, since $k^{b}$ and $k^{*}$ are close to each other (by assumption), an initial level of capital $k_{0}$ that is close to one of them is close to both and may set in motion a dynamics converging towards either $k^{*}$ or $k^{b}$. We now analyze the implications of the crowding out of productive labor by the financial sector for the dynamic efficiency of rational bubbles.

\section{Labor crowding out and dynamic efficiency}

In the limiting case where the financial sector is perfectly competitive (i.e., $\theta=0$ ), the size of the financial sector is zero and our model collapses into a version of Diamond's (1965). Consequently, the standard results applies that rational bubbles can exist only to the extend that they restore dynamic efficiency (Tirole, 1985). The question that we ask in this Section is: Do bubbles keep their efficiency properties when the market power of financiers allows them to seize part of the free lunch generated by asset bubbles?

It would seem, at first sight, that the answer should be "yes": since the bubbly equilibrium is associated with a higher productive rate than the bubbleless equilibrium, and that the overall

\footnotetext{
${ }^{8}$ See Caballero et al. (2005) for a similar approach, based on linarizing the relevant systems around two points that are distinct from, but arbitrarily close to, each other.
} 
surplus associated with this higher rate is shared between financiers and workers, agents in both sectors should benefit (or at least not suffer) from the bubble. In short, it would seem that the size of rent extraction by the financial sector should affect the way the efficiency gains associated with the bubble are shared amongst agents, but not the dynamic efficiency of the bubble per se.

This reasoning is wrong, however, for it ignores the effects of rent extraction by the financial sector on occupational choices and the implied distortion in the allocation of labor across sectors. As a first illustration of this potential welfare loss, assume that financiers are able to extract the largest possible rent, i.e., $\theta=1$. Then, equations (11) and (18) imply that consumption in the bubbleless steady state equilibrium is $c^{*}(1)=\lambda \omega\left(k^{*} / \ell^{*}\right)$, while consumption in the bubbly equilibrium is $c^{b}(1)=\lambda \omega\left(k^{b} / \ell^{b}\right)$. Since $k^{b} / \ell^{b}<k^{*} / \ell^{*}$ and $\omega^{\prime}(k / \ell)<0$, it follows that $c^{b}(1)<c^{*}(1)$ and hence rational bubbles cannot be dynamically efficient (i.e., some generations, possibly located far into the future, are better off without rather than with bubbles). The following proposition generalizes this reasoning for the case where $\theta<1$.

Proposition 2. The bubbly steady state has higher individual consumption than the bubbleless steady state if and only if rent extraction by the financial sector is not too large, i.e., if and only if $\theta<\theta^{*}$, where $\theta^{*} \in(0,1)$.

Proof. We must compare $c^{*}(\theta)$ (defined by equation (11)) and $c^{b}(\theta)$ (given by equation (18)) for $\theta \in[0,1]$. For $\delta, n$ and $\lambda$ given, $c^{*}(\theta)$ and $c^{b}(\theta)$ are continuous and linearly decreasing in $\theta \in[0,1]$, while $c^{b}(0)>c^{*}(0)$ and $c^{b}(1)<c^{*}(1)$ (see Figure 3 ). The first inequality is necessarily true from the asymptotic efficiency of bubbles in the Diamond-Tirole economy (which we recover when $\theta=0)$. The second inequality is equivalent to $\omega\left(f^{\prime-1}(n+\delta)\right)<\omega\left(\gamma^{-1}(1+n)\right)$, which is also true under Assumption (A3) since $\omega^{\prime}()=.-f^{\prime \prime}()>$.0 . Hence there is a unique $\theta^{*} \in(0,1)$ such that $c^{b}\left(\theta^{*}\right)=c^{*}\left(\theta^{*}\right)$, to the left (right) of which $c^{b}(\theta)>(<) c^{*}(\theta)$. QED

The central implication of Proposition 2 is that the bubbleless equilibrium cannot be dynamically efficient when rent extraction by the financial sector is too severe. This is because, given $\theta>\theta^{*}$ and $k_{0}$ close to both $k^{b}$ and $k^{*}$, convergence towards $k^{b}$ necessarily implies a consumption loss in finite time, relative to convergence towards $k^{*}$.

The consumption loss incurred by generations located sufficiently far into the future when $\theta>\theta^{*}$ does obviously not imply that all generations necessarily suffer from the bubble. In our model, bubbles affect welfare through two competing forces: they crowd out of productive capital efficiently, but crowd out productive labor inefficiently. Ultimately, the welfare impact of bubbles along the transition towards the steady state depends on the relative strength of these two forces at different points in time. 


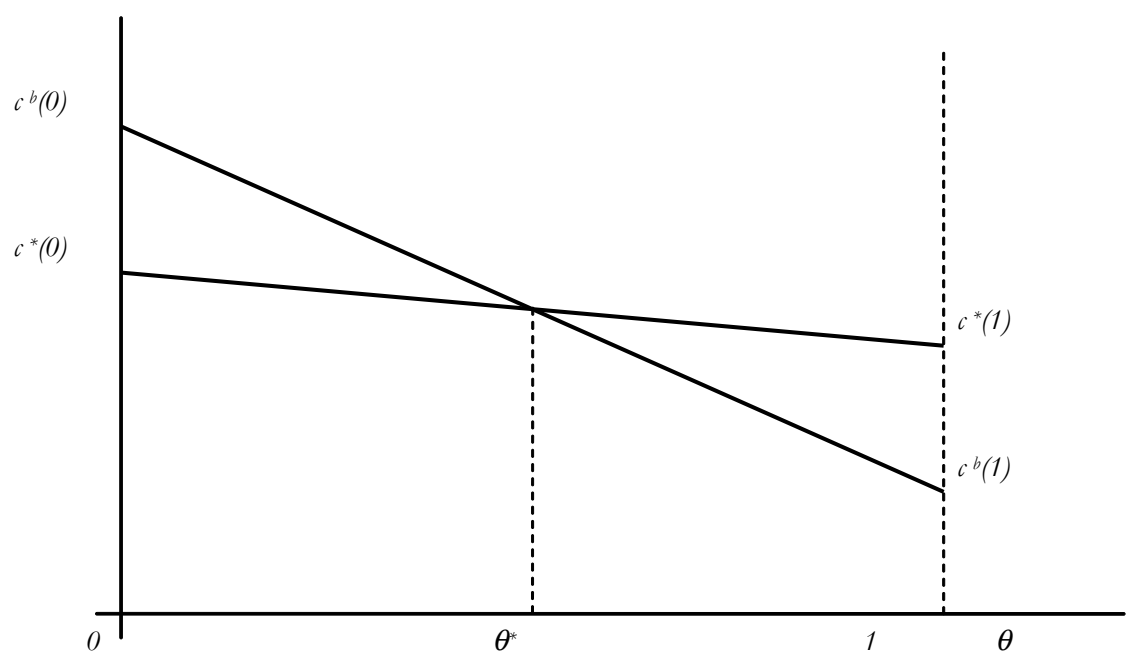

Figure 3: $c^{*}(\theta)$ and $c^{b}(\theta)$

Let us illustrate this point by means of the following example, which shows how early generations may benefit from the bubble, even though $\theta>\theta^{*}$ and hence late generations are bound to suffer from it. Assume that $k_{0}=K_{0} / N_{0}=k^{*}$, so that $c_{t}=c^{*}$ in (11) for all $t \geq 1$ if the economy settles on the bubbleless dynamics at date 0 . This path is represented by the bold horizontal lines in Figure 4. From equation (11), as $\theta$ is raised, the $c^{*}$-line shifts downwards and workers' expected consumption at all dates falls.

Now consider what happens in the bubbly equilibrium. From equation (18), the asymptotic consumption level of workers, represented by the $c^{b}$-line (dotted line), shifts downwards as $\theta$ increases; and by Proposition 2, it shifts more than the $c^{*}$-line whenever $\theta>\theta^{*}$. In this situation, some future generations are bound to incur a welfare loss if the economy settles on the bubbly equilibrium.

The opposite occurs in the short-run. Indeed, use (5) and (9) to write the consumption of workers born at date 0 as follows:

$$
c_{1}(\theta)=\omega\left(\frac{k_{0}}{\ell_{0}}\right)\left[\theta \lambda+(1-\theta)\left(f^{\prime}\left(\frac{k_{1}}{\ell_{1}}\right)+1-\delta\right)\right]=\omega\left(\frac{k_{0}}{\ell_{0}}\right)\left(\frac{\lambda \ell_{0}}{\ell_{0}+\theta-1}\right) .
$$

Since $\omega^{\prime}(k / \ell)>0$ while $k_{0}$ is given this last equation implies that consumption of individuals born at date 0 decreases with the size of the productive sector, $\ell_{0}$. We can then show that the size of the productive sector at date zero is smaller in the bubbly equilibrium than in the bubbleless equilibrium, so that the consumption of individuals born at date zero is always higher in the bubbly equilibrium than in the bubbleless equilibrium. This can be proven by contradiction. First, let us define the variable $x_{t} \equiv k_{t} / \ell_{t}$, so that $\hat{x}_{t}=\hat{k}_{t}-\hat{\ell}_{t}$, and note that for $k_{0}=k^{*}$ we have $x_{1}^{*}=k_{0} / \ell_{0}^{*}=x^{*}$ 
in the bubbleless equilibrium. ${ }^{9}$ In the bubbly equilibrium, we have $x_{1}^{b}=x^{b}+\tilde{p}_{1}\left(k_{0} / \ell_{0}^{b}-x^{b}\right) .{ }^{10}$ Now, suppose that $\ell_{0}^{b}>\ell_{0}^{*}$. From equation (9), this would imply that $x_{1}^{b}>x^{*}$, that is,

$$
x^{b}+\tilde{p}_{1}\left(\frac{k_{0}}{\ell_{0}^{b}}-x^{b}\right)>x^{*} \Leftrightarrow \tilde{p}_{1}\left(x^{*} \frac{\ell_{0}^{*}}{\ell_{0}^{b}}-x^{b}\right)>x^{*}-x^{b} .
$$

We know from equation (19) that $\tilde{p}_{1}<1$ and from Proposition 1 that $x^{*}-x^{b}>0$. Thus, inequality (20) cannot hold for $\ell_{0}^{b}>\ell_{0}^{*}$. Hence, it must be the case that $\ell_{0}^{b}<\ell_{0}^{*}$ and thus $c_{1}^{b}(\theta)>$ $c_{1}^{*}(\theta)$.

After date 0, factor payments in the bubbly equilibrium gradually (and monotonically) adjust towards their steady state values (since convergence is monotonic in $k_{t}$ ). Given this gradual adjustment, several generations may enjoy the consumption boom generated by the early stages of the bubble. When $\theta<\theta^{*}$ (i.e., rents are small), we have that $c^{b}(\theta)>c^{*}(\theta)$ and individual consumption may at all dates be higher in the bubbly equilibrium than in the bubbleless equilibrium (this situation is depicted in the left hand panel of Figure 4); when such is the case, the standard result that the bubbly equilibrium is dynamically efficient while the bubbleless equilibrium is not applies. However, when $\theta>\theta^{*}, c^{b}(\theta)$ lies below $c^{*}(\theta)$ and the bubbly equilibrium is bound to lose its welfare-improving properties (right hand panel of Figure 4). To summarize, when the initial stock of capital is close to the steady state value of the bubbleless equilibrium, the bubbly path is associated with higher consumption per worker in the short run, but bubbles reduce welfare in the long run when the market power of financiers is too large.

\section{$5 \quad$ Asset bubble and income inequalities}

In this section, we extend the analysis above in order to study the impact of bubbles on income inequalities. The starting point of this extension is the observation by Philippon and Reshef's (2008) that the U.S. financial sector has been highly skill-intensive in the past couple of decades, following of the high pace of deregulation and financial innovation over the period. We introduce this feature into our analysis by dividing the working population into "skilled" and "unskilled" individuals, and by assuming that the productive sector makes use of both labor types while asset trading can be carried out by skilled labor only. In short, skilled individuals have the ability choose between becoming a "managers" or a "banker", while unskilled individuals hold mostly non-transferable (i.e., industry-specific) competences and cannot move out of the productive sector. In this context, an asset bubble triggers a flight of skilled labor into the financial sector, raising the scarcity of

\footnotetext{
${ }^{9}$ The proof also works when $k_{0}$ is in the vicinity of $k^{*}$.

${ }^{10}$ The latter expression directely follows from local equilibrium dynamics of the bubbly equilibrium, in which $\hat{k}_{t}=\tilde{p}_{1} \hat{k}_{t-1}$ and $\hat{\ell}_{t}=\mu \hat{k}_{t}$, where $\mu$ is a constant. This implies that $\hat{x}_{t+1}=\tilde{p}_{1} \hat{x}_{t}$, and hence $x_{1}^{b}=x^{b}+\tilde{p}_{1}\left(x_{0}^{b}-x^{b}\right)$, where $x_{0}^{b}=k_{0} / \ell_{0}^{b}$.
} 


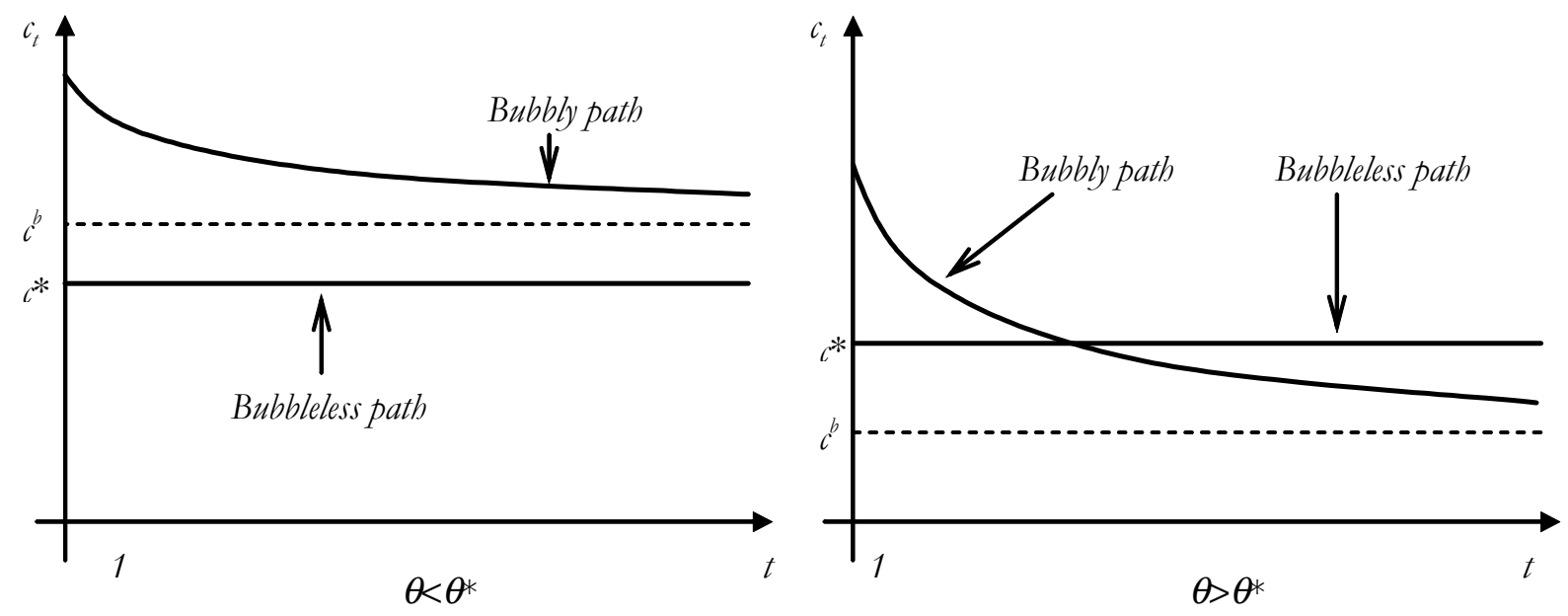

Figure 4: Consumption dynamics

skilled labor in the productive sector. In consequence, the marginal product of skilled (unskilled) labor is raised (diminished), the skill premium increases, possibly to the benefit of skilled and the detriment of the unskilled.

\subsection{Labor allocation under skill heterogeneity}

There are $N_{t}$ skilled individuals and $L_{u, t}=u N_{t}$ unskilled individuals in the population (hence total population is now $(1+u) N_{t}$ ). We now use $L_{t}$ to denote the number of skilled workers engaged in production. With this notation, which allows us to directly generalize the previous model, $\ell_{t}=L_{t} / N_{t}$ and $1-\ell_{t}$ are now the shares of skilled workers engaged in production and finance, respectively, while skilled and unskilled workers are in proportion $1 /(1+u)$ and $u /(1+u)$ in the population, respectively. Similarly, we now use $w_{t}$ to denote the wage of skilled workers and $w_{u, t}$ that of unskilled workers.

Production now requires both labor types, and for simplicity we assume that the production function is of the form:

$$
Y_{t}=A K_{t}^{\alpha} L_{t}^{\beta} L_{u, t}^{1-\alpha-\beta}
$$

or, in intensive form, $y_{t}=\Omega k_{t}^{\alpha} \ell_{t}^{\beta}$, with $\Omega \equiv A u^{1-\alpha-\beta}$. First, equating the marginal product of capital to the user cost of capital gives the following gross productive rate:

$$
1+r_{t}=\alpha \Omega k_{t}^{\alpha-1} \ell_{t}^{\beta}+1-\delta .
$$

Second, equating the marginal product of each labor type to the corresponding real wages, we find that the equilibrium skill premium in this economy is:

$$
\frac{w_{t}}{w_{u, t}}=\frac{\beta u}{(1-\alpha-\beta) \ell_{t}} \text {. }
$$


Finally, since $\ell_{t} \in[0,1]$ we can make sure that skilled workers always earn a higher wage than unskilled workers by assuming that

$$
u>(1-\alpha-\beta) / \beta
$$

If (A4) did not hold, unskilled labor could be so scarce, and consequently well remunerated in equilibrium, that skilled workers would prefer to go for unskilled jobs in the productive sector than working in the financial sector; this would lead the size of the latter to shrink to zero.

Equation (23) indicates that the skill premium is increased as the share of skilled workers in the productive sector goes down. In other words, increases in the size of the financial sector raise wage inequalities. This occurs for two reasons. First, for a given quantity of capital and unskilled labor in production, a reduction in the availability of skilled labor in that sector raises its relative price, $w_{t}$. Second, a lower level of skilled labor in the productive sector reduces the productivity of unskilled labor and hence the corresponding real wage, $w_{u, t}$.

As is shown in Appendix A1, the bargaining outcome that generates the equilibrium interest rate, $\rho_{t+1}$, as a function of the productive rate, $r_{t+1}$, is independent of the size of individual savings brought to the financier (equal to $w_{t}$ or $w_{u, t}$ here); hence equations (3)-(4) also apply to the economy with two labor types and uniquely determines the interest rate $\rho_{t+1}$. We denote by $c_{u, t+1}=w_{u, t}\left(1+\rho_{t+1}\right)$ and $c_{t+1}=w_{t}\left(1+\rho_{t+1}\right)$ the terminal consumption of an unskilled worker and that of a skilled worker engaged in production, respectively. There are $N_{t}-L_{t}$ financiers, who extract the intermediation margin $r_{t+1}-\rho_{t+1}$ and meet depositors according to the same random matching process as before. For any particular financier, the expected number of matches with skilled worker engaged in production is $\ell_{t} /\left(1-\ell_{t}\right)$, while any match with a skilled leads to a deposit collection of $w_{t}$. On the other hand, the expected number of matches with unskilled workers is $u /\left(1-\ell_{t}\right)$, while any match with an unskilled worker leads to the collection of $w_{u t}$ units of savings. Hence, using (23) we find that the (expected) terminal consumption of a skilled worker in the financial sector is:

$$
\begin{aligned}
\mathbb{E}_{t}\left(c_{t+1}^{f}\right) & =\left(\frac{\ell_{t} w_{t}+u w_{u, t}}{1-\ell_{t}}\right)\left(r_{t+1}-\rho_{t+1}\right) \\
& =\left(\frac{1-\alpha}{\beta}\right) \frac{\ell_{t}}{1-\ell_{t}} w_{t}\left(r_{t+1}-\rho_{t+1}\right),
\end{aligned}
$$

which generalizes equation (6) above.

Since by assumption the demand for unskilled labor by the financial sector is zero, the absence of arbitrage opportunities across alternative career choices applies to skilled workers only. Equating $c_{t+1}$ and $\mathbb{E}_{t}\left(c_{t+1}^{f}\right)$, we find that in equilibrium the share of skilled workers choosing to work in the financial sector is

$$
1-\ell_{t}=\frac{(1-\alpha) \theta\left(1+r_{t+1}-\lambda\right)}{(1-\alpha-\beta) \theta\left(1+r_{t+1}-\lambda\right)+\beta\left(1+r_{t+1}\right)}
$$


which generalizes equation (7) above. It is easy to check from (24) that $\partial \ell_{t} / \partial r_{t+1}<0$, that is, a higher productive rate attracts more skilled workers into finance, due to the greater intermediation margin to be earned there. Taken together, equations (23) and (24) indicate that a higher productive rate is associated with a greater skill premium. Moreover, since the interest rate is the same for all workers, we have $c_{t+1} / c_{u, t+1}=w_{t} / w_{u, t}$, so that wage inequalities are directly reflected into consumption inequalities.

\subsection{Bubbleless equilibrium}

Using the expressions for $w_{t}$ and $w_{u, t}$ derived from (21) and rearranging, we find that total savings are $w_{u, t} L_{u, t}+w_{t} L_{t}=(1-\alpha) w_{t} L_{t} / \beta$. In the bubbleless equilibrium all these savings are invested into next period's capital stock, $K_{t+1}$. Hence the capital accumulation equation can be written as:

$$
(1+n) k_{t+1}=(1-\alpha) \Omega k_{t}^{\alpha} \ell_{t}^{\beta}
$$

The dynamics of the bubbleless equilibrium is described by a two-dimensional system formed by the labor allocation equation (24) (with the productive rate $r_{t+1}$ given by (22)) and the capital accumulation equation (25).

We solve the model with skill heterogeneity in the same way as we solved the basic model. We first compute the steady state of the bubbleless equilibrium. It will then be compared to the bubbly analogue, with particular attention being paid to asymptotic levels of capital and consumption per worker. Second, we examine the local stability of this equilibrium to show that it exists and is unique under condition (12). This second step is carried out in Appendix C and, for the sake of conciseness, not detailed here.

From equations (22) and (25), the value of the productive rate at the bubbleless steady state is:

$$
1+r^{*}=\frac{\alpha(1+n)}{(1-\alpha)}+1-\delta
$$

The steady state value of the other variables can then be computed sequentially: the share of skilled labor in production, $\ell^{*}$, is uniquely determined by (24) and the value of $r^{*}$, while capital per worker, $k^{*}$, can be computed from $r^{*}$ and $\ell^{*}$ using (22). Finally, note that assumption (A2) is still assumed to hold here, i.e., $\alpha(1+n) /(1-\alpha)+1-\delta>\lambda$.

\subsection{Bubbly equilibrium}

In the bubbly equilibrium, aggregate savings, $(1-\alpha) w_{t} L_{t} / \beta$, are used to finance the purchase of capital stock, $K_{t+1}$, and the aggregate bubble $B_{t}$. Hence the capital accumulation equation becomes:

$$
b_{t}+(1+n) k_{t+1}=(1-\alpha) \Omega k_{t}^{\alpha} \ell_{t}^{\beta}
$$


where, by our normalization, $b_{t}=B_{t} / N_{t}$ now denotes the bubble per skilled worker. The absence of arbitrage opportunities for speculators implies that the dynamics of the bubble must be

$$
b_{t+1}=\left(\frac{1+r_{t+1}}{1+n}\right) b_{t}
$$

Equation (26)-(27), together with (22) and (24), fully describe the dynamics of the bubbly equilibrium.

As usual, the steady state of the bubbly equilibrium satisfies $b_{t+1}=b_{t}$ and hence the "goldenrule" relation $r^{b}=n$. The existence of asymptotically bubbly equilibria is ensured if the value of the bubble per skilled worker in the steady state, $b$, is positive. From (22) and (26), this is the case if and only if the productive rate in the bubbleless steady state lies below the golden rule interest rate, i.e.,

$$
r^{*}=\frac{\alpha(1+n)}{(1-\alpha)}-\delta<r^{b}=n .
$$

Again, the bubbly steady state $\left(k^{b}, \ell^{b}, b\right)$ can be computed sequentially as follows. Substituting $n$ for $r_{t+1}$ in (24) gives $\ell^{b}$. With $\ell^{b}$ and $r^{b}$ known, the steady state counterpart of (22) uniquely determine $k^{b}$. Finally, $k^{b}$ and $\ell^{b}$ can be substituted into the steady state counterpart of (26) to find $b$. Moreover, and as is shown in Appendix $\mathrm{C}$, the bubbly steady state is determinate under condition (12) provided that $k^{b}$ is sufficiently close to $k^{*}$ (or, equivalently, that $b$ is sufficiently small). This establishes the local uniqueness of the asymptotically bubbly equilibrium.

\subsection{Dynamic efficiency}

The central implication of the heterogenous skill model is that asset bubbles affect relative wages and consumption levels through their effect on the allocation of skilled workers across sectors. We focus here on the comparison of steady state consumption levels, and rely on the local stability of both equilibria to argue that, starting from $k_{0}$ sufficiently close to $k^{*}$ and $k^{b}$, these consumption levels will asymptotically converge towards their steady state value. The following proposition establishes that, as a result of rising income inequalities, unskilled workers are the first to bear the cost of the misallocation of labor generated by asset bubbles.

Proposition 3. There exists a threshold level for the market power of financiers, denoted by $\theta_{u}^{*} \in(0,1)$, such that the consumption of unskilled workers is lower in the bubbly than in the bubbleless steady state whenever $\theta>\theta_{u}^{*}$. In the vicinity of $\theta=\theta_{u}^{*}$ the steady state consumption level of skilled workers is higher in the bubbly steady state than in the bubbleless steady state.

Proof. In Appendix D.

Proposition 3 identifies a new source of breakdown of dynamic efficiency under endogenous occupational choice, namely, the fact that the bubble may be harmful to unskilled workers even 
when it benefits skilled workers. This is notably the case when $\theta$ is higher than, but close to $\theta_{u}^{*}$. Note also that the opposite cannot occur: because all depositors are paid the same interest rate while the bubble raises wage inequalities, it cannot be that the bubble raises the consumption of the unskilled while lowering that of the skilled (relative to the bubbleless equilibrium). Importantly, the proposition does not establish an upper threshold of $\theta$ above which skilled workers would lose; in fact, one can easily construct examples in which the consumption of the skilled is higher in the bubbly than in the bubbleless equilibrium for all possible values of $\theta$ (see below); in contrast, there always exists such a threshold for the unskilled.

To get further insight into the redistributive effects of asset bubbles under heterogenous skills, it may be useful to draw the values of key steady state variables as a function of $\theta$, the market power of financiers. Our first example, which uses $A=u=\delta=1, \alpha=1 / 3, \beta=1 / 2, \lambda=0.5$ and $n=0.1$, is depicted in Figure 5. For all values of $\theta$, the bubbly steady state (bold curves) is associated with a larger financial sector, lower wages and greater wage inequalities than the bubbleless steady state. Crucially, there are now two threshold levels for $\theta$ (instead of one as in Figure 2): $\theta_{u}^{*}$, above which unskilled workers asymptotically suffer from the bubble, and $\theta_{s}^{*}$, above which skilled workers asymptotically suffer from the bubble. Since $\theta_{u}^{*}<\theta_{s}^{*}$ (as is consistent with Proposition 3 ), there is a range of market powers within which the bubbly steady state is beneficial to the skilled but detrimental to the unskilled, relative to the bubbleless steady state.

The second example, depicted in Figure 6, uses the same parameters as those of the first example except for the fact that we set $\beta=1 / 3$ and $u=1.2$. In this situation, we still have a threshold $\theta_{u}^{*} \in(0,1)$ for the unskilled, but no such a threshold for the skilled: these always benefit from the bubble asymptotically. A central difference with the previous example, and one that is responsible for this result, is that here bubbles turn out to raise the wage income of skilled workers for sufficiently high values of $\theta$. To understand why this is the case, recall that the skilled wage is $w_{t}=\beta \Omega k_{t}^{\alpha} \ell_{t}^{\beta-1}$ in equilibrium. On the one hand, the bubbly steady state has lower capital per worker than the bubbleless steady state, which pushes this wage down; on the other hand, the bubbly steady state has fewer skilled workers in the production sector, which raises their marginal product and hence pushes their wage up. Ultimately the impact of the bubble on the (steady state) equilibrium wage of skilled workers depends on these two forces. When the market power of financiers is sufficiently strong, the brain drain from production to speculation that takes place in the bubbly equilibrium may cause the second effect to dominate, resulting in higher wages and higher consumption levels. In other words, the model explains not only why bubbles raise income inequalities, but also how they may lead to an absolute increase in both the wage and capital income of skilled workers. Hence, our model is consistent with the observed rise in U.S. top incomes that occurred from the mid-1990s to the late 2000s (Atkinson, Piketty and Saez, 2010) and the related 

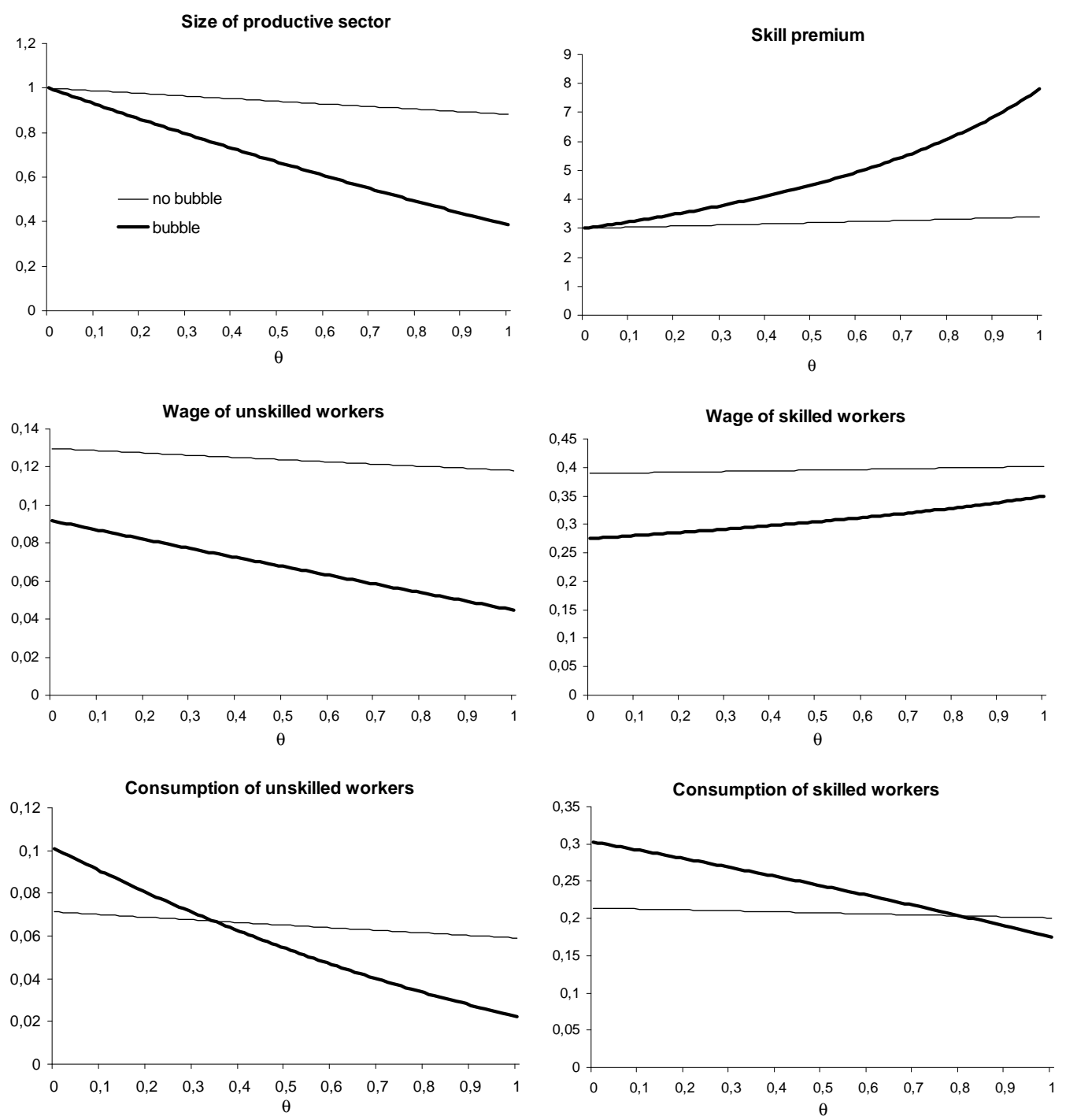

Figure 5: Example of steady state with $A=u=\delta=1, \alpha=1 / 3, \beta=1 / 2, \lambda=0.5$ and $n=0.1$

increase in wage inequalities in the U.S. labor market (Autor, Katz and Kearney, 2006), which precisely occurred at a time when the financial sector attracted much skilled labor.

\section{Concluding remarks}

This paper has analyzed the effect of rational bubbles in an economy where asset trading requires specialized intermediaries having optimally chosen this occupation. Our main result is that while asset bubbles raise the attractiveness of the financial sector and divert labor out of productive activities and into speculative ones, the extent and social costs of this diversion crucially depend on the size of the speculative rents that intermediaries are able to extract in equilibrium. Ignoring 

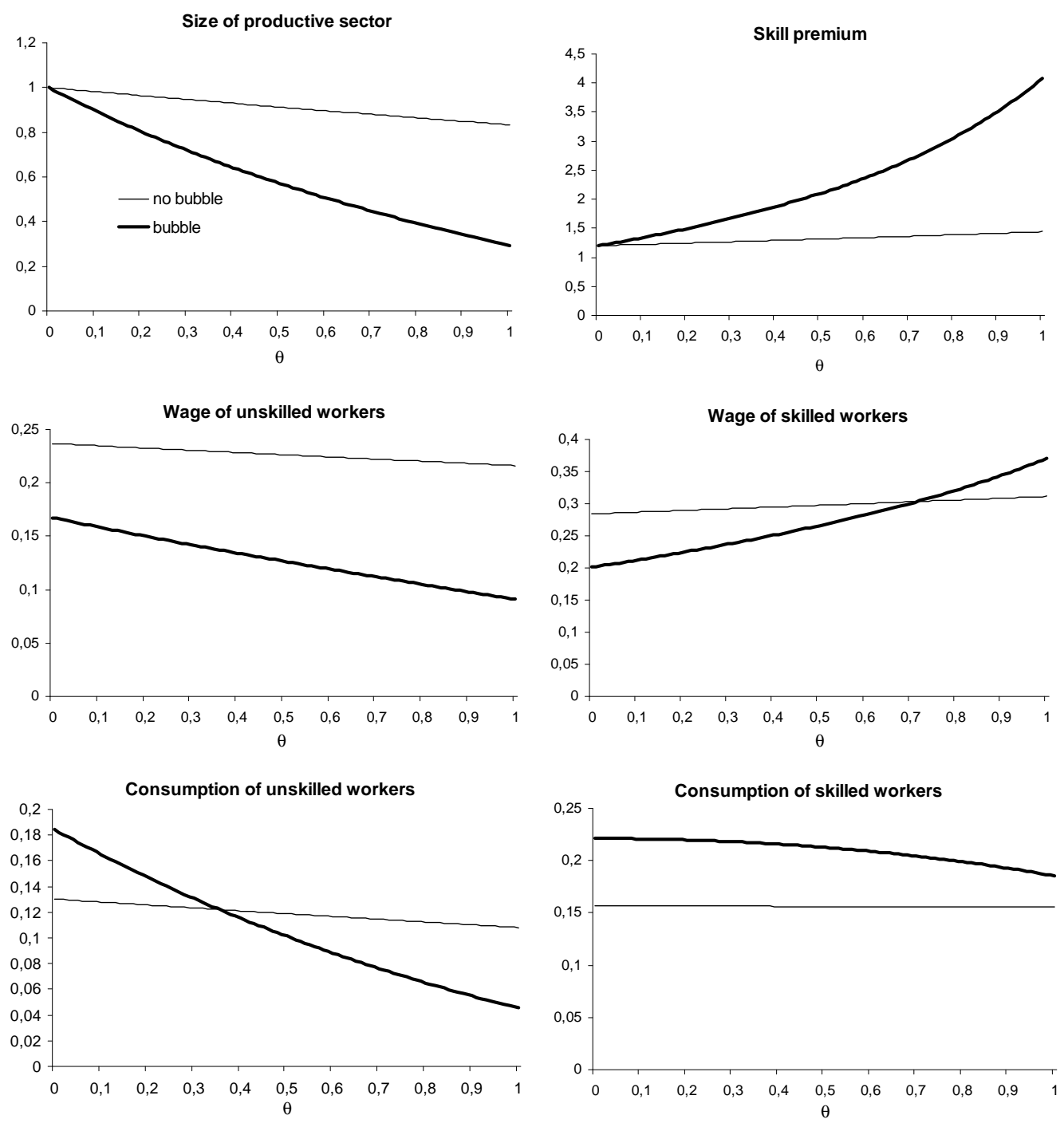

Figure 6: Example of steady state with $A=\delta=1, \alpha=1 / 3, \beta=1 / 3, \lambda=0.5, u=1.2$ and $n=0.1$. 
skill heterogeneity, we showed that bubbles lose their Pareto-improving properties as soon as the "labor crowding out" induced by rents in the financial sector becomes sufficiently serious to offset the usual beneficial effects of capital crowding out. Hence, while our analysis lends support to the conventional view that asset bubbles may be detrimental to productive activities, it also suggests that part of the issue lies in the interaction of bubbles with rents, rather than in the existence of bubbles per se. Finally, introducing skill heterogeneity allowed us to show that bubbles raise income inequalities, so that not all agents are equally affected by the occurrence of bubbles. In particular, low-skilled workers are the first to be hit by the worsening of the rent-extraction problem caused by the asset bubble. This central role of rents in determining the welfare and redistributive effects of bubbles may provide another justification for regulating the financial sector, complementary to those based on financial stability concerns. 


\section{References}

[1] Atkinson, Antony B., Thomas Piketty and Emmanuel Saez, 2009, Top Incomes in the Long Run of History, NBER Working Paper 15408.

[2] Autor, David, H., Lawrence F. Katz and Melissa S. Kearney, 2006, The Polarization of the U.S. Labor Market, American Economic Review, Papers and Proceedings, vol 96(2): 189-194.

[3] Baumol, William J., 1990, Entrepreneurship: Productive, Unproductive, and Destructive, Journal of Political Economy, vol 98(5): 893-921.

[4] Blanchard, Olivier, 2009, The Crisis: Basic Mechanisms, and Appropriate Policies, IMF Working Paper no 09/80, April.

[5] Brunnermeier, Markus, 2009, Deciphering the liquidity and credit crunch 2007-2008, Journal of Economic Perspectives, vol 23(1): 77-100.

[6] Brunnermeier, Markus and Stefan Nagel, 2004, Hedge Funds and the Technology Bubble, Journal of Finance, vol 59(5): 2013-2040.

[7] Caballero, Ricardo J., Emmanuel Farhi and Mohamad Hammour, 2006, Speculative Growth: Hints from the U.S. Economy, American Economic Review, vol 96(4): 1159-1192.

[8] Diamond, Peter, 1965, National Debt in a Neoclassical Growth Model, American Economic Review, vol 55(5): 1126-50.

[9] Duflo, Esther, 2008, Too Many Bankers?, VoxEU.org.

[10] Fahri, Emmanuel and Jean Tirole, 2009, Bubbly Liquidity, IDEI Working Paper no 572.

[11] Femminis, Gianluca, 2002, Monopolistic Competition, Dynamic Inefficiency and Asset Bubbles, Journal of Economic Dynamics and Control, vol 26: 985-1007.

[12] Goldin, Claudia and Lawrence Katz, 2008, Transitions: Career and Family Life Cycles of the Educational Elite, American Economic Review, vol 98(2): 263-269.

[13] Greenlaw, David, Ian Hatzius, Anil K. Kashyap and Hyun Song Shin, 2008, Leveraged Losses: Lessons from the Mortgage Market Meltdown, U.S. Monetary Policy Forum Report, vol 2: 7-59.

[14] Grossman, Gene and Noriyuki Yanagawa, 1993, Asset Bubbles and Endogenous Growth, Journal of Monetary Economics, vol 31(1): 3-19. 
[15] Hall, R.E. (1977), An aspect of the economic role of unemployment, in The Microeconomic Foundations of Macroeconomics, G.H. Hartcourt (ed.), MacMillan.

[16] Krugman, Paul, 2009, Making Banking Boring, New York Times, April, 10.

[17] Ofek, Eli and Matthew Richardson, 2003, DotCome Mania: The Rise and Fall of Internet Stock Prices, Journal of Finance, vol 58(3): 1113-1137.

[18] Olivier, Jacques, 2000, Growth-enhancing Bubbles, International Economic Review, vol 41(1): 133-151.

[19] Pastor, Lubos and Pietro Veronesi, 2006, Was there a NASDAQ bubble in the late 1990s?, Journal of Financial Economics, vol 81: 61-100.

[20] Philippon, Thomas, 2007, Engineers vs. Financiers: Should the Financial Sector be Taxed or Subsidized?, October 2007.

[21] Philippon, Thomas, 2008, The Evolution of the US Financial Industry from 1860 to 2007, NYU Stern Business School mimeograph.

[22] Philippon, Thomas and Ariell Reshef, 2008, Wages and Human Capital in the U.S. Financial Industry: 1909-2006, NYU Stern Business School mimeograph.

[23] Piketty, Thomas and Emmanuel Saez, 2003, Income Inequality in the United States, 1913-1998, Quarterly Journal of Economics, vol 118(1): 1-39

[24] Saez, Emmanuel, 2009, Striking It Richer: The Evolution of Top Incomes in the United States, Working Paper.

[25] Saint-Paul, Gilles, 1992, Fiscal Policy in an Endogenous Growth Model, Quarterly Journal of Economics, vol 107(4): 1243-1259.

[26] Samuelson, Paul, 1958, An Exact Consumption-Loan Model of Interest with or without the Social Contrivance of Money, Journal of Political Economy, vol 66: 467-482.

[27] Sen, Partha, 2002, Welfare-improving debt policy under monopolistic competition, Journal of Economic Dynamics and Control, vol 27: 143-156.

[28] Shiller, Robert, 2000, Irrational Exuberance, Princeton University Press.

[29] Tett, Gillian, 2009, A Chance for Bankers to Refocus their Talents, Financial Times, April 6.

[30] Tirole, Jean, 2005, The Theory of Corporate Finance, Princeton University Press. 
[31] Tirole, Jean, 1985, Asset Bubbles and Overlapping Generations, Econometrica, vol 53(6): 1499-1528.

[32] Ventura, Jaume, 2003, Economic Growth with Bubbles, Working Paper.

[33] Wasmer, Etienne and Philippe Weil, 2004, The Macroeconomics of Labor and Credit Market Imperfections, American Economic Review, vol 94(4): 944-63.

[34] Weil, Philippe, 1989, Overlapping Families of Infinitely-Lived Agents, Journal of Public Economics, vol 38(2): 183-98.

[35] Weil, Philippe, 1987, Confidence in the Real Value of Money in an Overlapping Generations Economy, Quarterly Journal of Economics, vol 52(1): 1-22. 


\section{Appendix}

\section{A. Matching and bargaining outcomes}

\section{A1. Baseline specification}

We work out the solution to the matching and bargaining process backwards. Consider the match between a financier and a depositor having reached the $\tau$ th bargaining round, and call $\rho_{\tau, t+1}$ the bargained interest rate resulting from the match. The depositor's payoff from the match is $w_{t}\left(1+\rho_{\tau, t+1}\right)$ and his outside option $w_{t} \lambda$, so his surplus from the match is $S_{\tau, t+1}^{w}=$ $w_{t}\left(1+\rho_{\tau, t+1}-\lambda\right)$. Since the financier's outside option is zero, his surplus from this match is $S_{\tau, t+1}^{f}=w_{t}\left(r_{t+1}-\rho_{1, t+1}\right)$. With a surplus share $\tilde{\theta}$, the financier extracts the payoff $\tilde{\theta}\left(S_{\tau, t+1}^{w}+\right.$ $\left.S_{\tau, t+1}^{f}\right)=\tilde{\theta} w_{t}\left(1+r_{t+1}-\lambda\right)$, which by definition is equal to $w_{t}\left(r_{t+1}-\rho_{\tau, t+1}\right)$. Hence the unit intermediation margin that a financier extracts from a match with a depositor in his $\tau$ th bargaining round is:

$$
r_{t+1}-\rho_{\tau, t+1}=\tilde{\theta}\left(1+r_{t+1}-\lambda\right)
$$

Now consider what happens in the $(\tau-1)$ th match of a depositor, and call $\rho_{\tau-1, t+1}$ the interest that results from the bargaining process. The depositor's gain from the match is $w_{t}\left(1+\rho_{\tau-1, t+1}\right)$ while the outside option is now $w_{t}\left(1+\rho_{\tau, t+1}\right)$ (i.e., what can be extracted from the following match), so the surplus from this $(\tau-1)$ th match is $S_{\tau-1, t+1}^{w}=w_{t}\left(\rho_{\tau-1, t+1}-\rho_{\tau, t+1}\right)$. On the other hand the financier's outside option on a particular match is still 0 , so his surplus from this match is $S_{\tau-1, t+1}^{f}=w_{t}\left(r_{t+1}-\rho_{\tau-1, t+1}\right)$. The condition that $S_{\tau-1, t+1}^{f}=\tilde{\theta}\left(S_{\tau-1, t+1}^{f}+S_{\tau-1, t+1}^{w}\right)$ gives the following intermediation margin to the financier:

$$
r_{t+1}-\rho_{\tau-1, t+1}=\tilde{\theta}\left(r_{t+1}-\rho_{\tau, t+1}\right)=\tilde{\theta}^{2}\left(1+r_{t+1}-\lambda\right)
$$

Note that for both parties the gain from this $(\tau-1)$ th match is higher than their outside options (i.e., $\rho_{\tau-1, t+1}>\rho_{\tau, t+1}$ and $r_{t+1}-\rho_{\tau-1, t+1}>0$ ), so both agree to strike a deal at this stage. By the same logic, repeated $\tau$ times, both parties agree to strike a deal at the first match, giving the financier an intermediation margin:

$$
\begin{aligned}
r_{t+1}-\rho_{1, t+1} & =\tilde{\theta}\left(r_{t+1}-\rho_{2, t+1}\right)=\tilde{\theta}^{2}\left(r_{t+1}-\rho_{3, t+1}\right)=\ldots \\
& =\tilde{\theta}^{\tau-1}\left(r_{t+1}-\rho_{\tau, t+1}\right)=\tilde{\theta}^{\tau}\left(1+r_{t+1}-\lambda\right)
\end{aligned}
$$

This is exactly equation (4) in the body of the paper since $\rho_{t+1}$, the prevailing interest rate, is the one that result from (all) depositors' unit gain from their first bargaining round, $\rho_{1, t+1}$. Equation (3) is a rewriting of (4). Combined with the expected payoff associated with either career (5)-(6), we get the labor allocation equation (7). 


\section{A2. Maximum financiers' capacity and minimal financial sector size}

In this appendix we modify the bargaining process leading to the labor allocation equation (7) to allow for a non-zero optimal financial sector size. First, we limit financiers' capacity by assuming that every financier can handle a maximum number of customers $\kappa>0$; this can be viewed as an extreme form of increasing marginal cost to intermediation, with the marginal cost being (normalized to) zero below and up until $\kappa$ clients and prohibitive above $\kappa$ clients. Second, we assume that financiers must cluster to form partnerships, or "banks". There is a large number of such banks (i.e., the typical bank has vanishingly small size), so that the probability that a depositor is re-matched with the same bank were the deal to fail is zero; hence for any bank the outside option in any match is zero, as in our baseline specification. However, the payoff risk generated by the randomness of the matching process is assumed to be fully diversified within the bank, so that $L_{t} /\left(N_{t}-L_{t}\right)=\ell_{t} /\left(1-\ell_{t}\right)$ is the ex post (rather than expected) number of matches for any financiers. Full risk diversification within the bank implies that we can treat financiers symmetrically; without this assumption, some financiers would be matched with less than $\kappa$ customers while some other would reach their maximum capacity and their would be ex post heterogeneity amongst financiers.

There are two regimes in this economy. The first regime is associated with relative large values of $\theta$ and generates sizeable frictional rents. In this situation the endogenous size of the financial sector (as determined by (7)) is such that financiers are in sufficiently large number (relative to the number of producers) for every financier to work below their maximum capacity. Hence the capacity constraint is not binding and the equilibrium outcome is as in the baseline specification presented in the body of the paper.

In the second regime, which is associated with relative low values of $\theta$, rents are too small to sustain a large financial sector. In this situation the bargaining process described in Section A1 and leading to the interest rate in (3) is no longer valid, because by assumption the marginal cost to intermediation would cause financiers' surplus to vanish. Instead, the allocation of labor across sector operates in a perfectly competitive fashion, with the equilibrium value of the interest rate being that which exactly ensures equal payoff prospects across carrier choices. With $\ell_{t} /\left(1-\ell_{t}\right)=\kappa$, equalization of (5) and (6) gives:

$$
1+\rho_{t+1}=\frac{\kappa\left(1+r_{t+1}\right)}{1+\kappa} .
$$

If $1+\rho_{t+1}$ were higher than $\kappa\left(1+r_{t+1}\right) /(1+\kappa)$, then the per-client intermediation margin would be too small to make finance worthwhile (given the maximum capacity of any financier), hence no worker would ever choose this occupation and no intermediation would take place; in this situation, producers would be ready to accept interest rate cuts until the last equality is restored and finance 
becomes a worthwhile activity. If, on the contrary, $1+\rho_{t+1}$ where lower than $\kappa\left(1+r_{t+1}\right) /(1+\kappa)$, then all workers would choose to work in the financial sector and financiers would end up with no client; then, competition amongst financiers would lead them to increase $1+\rho_{t+1}$ (i.e., to decrease their unit margin) until the last equality is restored. Since in the second regime the financial sector has size $1-\ell_{t}=1 /(1+\kappa)$, the equilibrium size of this sector under capacity constraint is:

$$
1-\ell_{t}=\max \left[\theta\left(1-\frac{\lambda}{1+r_{t+1}}\right), \frac{1}{1+\kappa}\right],
$$

which generalizes equation (7). Note that the latter equation defines the minimal value of the market friction index $\theta$, below which financiers are at their maximum capacity:

$$
\bar{\theta}=\frac{1+r_{t+1}}{(1+\kappa)\left(1+r_{t+1}-\lambda\right)}
$$

To summarize: with a maximum capacity constraint the size of the financial sector, $1-\ell_{t}$, as a function of $\theta$ is continuous and kinked. It is constant and equal to $1 /(1+\kappa)$ for $\theta \in[0, \bar{\theta})$, and linearly increasing in $\theta$ (with slope $1-\lambda /\left(1+r_{t+1}\right)$ ) for $\theta \in[\bar{\theta}, 1]$. Were frictional rents to be removed by an almighty social planner, the optimal size of the financial sector would be $1-\ell_{t}=1 /(1+\kappa)$, and thus decreasing in financiers' capacity. Our baseline case is recovered as $\kappa \rightarrow+\infty$, so that $\bar{\theta}=0$ and hence $\theta \geq \bar{\theta} \forall \theta \in[0,1]$.

The analysis in the body of the paper exactly applies to this alternative specification provided that $\theta>\bar{\theta}$ (i.e., $\theta$ and $\kappa$ are jointly sufficiently large) at the bubbleless steady state: since $\partial \bar{\theta} / \partial r_{t+1}<0$ while the bubbly steady state has higher productive rate than the bubbleless steady state, this would imply that $\theta>\bar{\theta}$ also at the bubbly steady state, and the capacity constraint would never bind in the vicinity of either. There is one implication of this specification that we do not analyze explicitly in the body of the paper but which may be of interest: the possibility that the capacity constraint binds in the bubbleless steady state but not in the bubbly steady state. In this situation, the bubbleless equilibrium is associated with an optimal financial sector size while the bubbly equilibrium has too large a financial sector. In contrast, in our baseline specification the financial sector is too large in both equilibria (although bubbles worsen the problem).

\section{B. Local dynamics of the basic model}

\section{B1. Bubbleless equilibrium}

We use hatted variables to denote proportional deviations of the corresponding variables from the steady state (e.g., $\left.\hat{k}_{t}=\left(k_{t}-k^{*}\right) / k^{*}\right)$. Linearizing $(8)$ and $(9)$ around $\left(k^{*}, l^{*}\right)$ yields:

$$
\hat{k}_{t+1}=\alpha^{*} \hat{k}_{t}+\left(1-\alpha^{*}\right) \hat{\ell}_{t}, A^{*} \hat{\ell}_{t}=\hat{k}_{t+1}-\hat{\ell}_{t+1}
$$


where

$$
\begin{aligned}
\alpha^{*} & \equiv \frac{\left(k^{*} / \ell^{*}\right) \omega^{\prime}\left(k^{*} / \ell^{*}\right)}{\omega\left(k^{*} / \ell^{*}\right)}, \epsilon^{*} \equiv-\frac{\left(k^{*} / \ell^{*}\right) f^{\prime \prime}\left(k^{*} / \ell^{*}\right)}{f^{\prime}\left(k^{*} / \ell^{*}\right)+1-\delta}, \\
A^{*} & \equiv \frac{1}{\epsilon^{*}}\left[1+\left(\frac{1-\theta}{\theta}\right)\left(\frac{f^{\prime}\left(\gamma^{-1}(1+n)\right)+1-\delta}{\lambda}\right)\right] .
\end{aligned}
$$

We write the linearized dynamics of the model as $\hat{x}_{t+1}=M \hat{x}_{t}$, where $\hat{x}_{t}=\left[\begin{array}{ll}\hat{k}_{t} & \hat{\ell}_{t}\end{array}\right]^{\prime}$ and

$$
M=\left[\begin{array}{cc}
\alpha^{*} & 1-\alpha^{*} \\
\alpha^{*} & 1-\alpha^{*}-A^{*}
\end{array}\right]
$$

The characteristic polynomial of $M$ is $P(p)=p^{2}-\left(1-A^{*}\right) p-\alpha^{*} A^{*}$ and has roots:

$$
p_{1,2}=\frac{1}{2}\left(1-A^{*} \pm \sqrt{\left(1-A^{*}\right)^{2}+4 \alpha^{*} A^{*}}\right) \text {. }
$$

Note that both roots are real, that $p_{1} \in(0,1)$ and that $p_{2}<-1$ if and only if $A^{*}\left(1+\alpha^{*}\right)>2$, which is inequality (12) in the body of the paper (when (12) is not satisfied we have $p_{2} \in(-1,0)$ and hence indeterminacy). The general solution of the linearized system is

$$
\hat{k}_{t}=c_{1} \frac{p_{1}+\alpha^{*}+A^{*}}{\alpha^{*}} p_{1}^{t}+c_{2} p_{2}^{t}, \quad \hat{\ell}_{t}=c_{1} \frac{p_{2}+\alpha^{*}+A^{*}}{\alpha^{*}} p_{1}^{t}+c_{2} p_{2}^{t}
$$

where $c_{1}$ and $c_{2}$ are two numbers whose value is determined by the initial value of $\hat{k}_{t}$ and the terminal value of $\hat{\ell}_{t}$. Since $\hat{\ell}_{\infty}=0$ and $p_{2}<-1$, one has $c_{2}=0$. Then:

$$
c_{1}=\frac{\alpha^{*} \hat{k}_{0}}{p_{1}+\alpha^{*}+A^{*}} .
$$

Substituting the values of $c_{1}$ and $c_{2}$ into (29) yields $\hat{k}_{t}=p_{1}^{t} \hat{k}_{0}$, which gives (14) in the body of the paper.

\section{B2. Bubbly equilibrium}

Let us first define $\alpha^{b}$ and $\epsilon^{b}$ as the same elasticities as those in (13) but evaluated at the bubbly steady state. The linearization of $(15)$ around $\left(k^{b}, \ell^{b}, b\right)$ gives:

$$
\hat{k}_{t+1}=\nu \alpha^{b} \hat{k}_{t}+\nu\left(1-\alpha^{b}\right) \hat{\ell}_{t}+(1-\nu) \hat{b}_{t}
$$

where

$$
\alpha^{b} \equiv \frac{\left(k^{b} / \ell^{b}\right) \omega^{\prime}\left(k^{b} / \ell^{b}\right)}{\omega\left(k^{b} / \ell^{b}\right)}, \epsilon^{b} \equiv-\frac{\left(k^{b} / \ell^{b}\right) f^{\prime \prime}\left(k^{b} / \ell^{b}\right)}{f^{\prime}\left(k^{b} / \ell^{b}\right)+1-\delta}, \nu \equiv \frac{\omega\left(k^{b} / \ell^{b}\right)}{(1+n)\left(k^{b} / \ell^{b}\right)}=\frac{\gamma\left(f^{\prime-1}(n+\delta)\right)}{(1+n)} .
$$

Note that $\nu>1$ since $\gamma\left(k^{*} / \ell^{*}\right)=1+n, \gamma\left(\right.$.) is decreasing in $k / \ell$ (by assumption) and $k^{b} / \ell^{b}<$ $k^{*} / \ell^{*}$ (i.e., the bubble asymptotically crowds out capital per producer). Next, linearizing (9) gives:

$$
\hat{k}_{t+1}-\hat{\ell}_{t+1}=A^{b} \hat{\ell}_{t}
$$


where:

$$
A^{b} \equiv \frac{1}{\epsilon^{b}}\left[1+\left(\frac{1-\theta}{\theta}\right) \frac{f^{\prime}\left(k^{b} / \ell^{b}\right)+1-\delta}{\lambda}\right]=\frac{1}{\epsilon^{b}}\left[1+\left(\frac{1-\theta}{\theta}\right) \frac{1+n}{\lambda}\right] .
$$

Finally, linearizing (16) yields:

$$
\hat{b}_{t+1}=\hat{b}_{t}-\epsilon^{b}\left(\hat{k}_{t+1}-\hat{\ell}_{t+1}\right)
$$

From the three linearized difference equations we can write the bubbly equilibrium in matrix form as $\left[\begin{array}{lll}\hat{k}_{t+1} & \hat{\ell}_{t+1} & \hat{b}_{t+1}\end{array}\right]^{\prime}=N\left[\begin{array}{lll}\hat{k}_{t} & \hat{\ell}_{t} & \hat{b}_{t}\end{array}\right]^{\prime}$, with:

$$
N=\left[\begin{array}{ccc}
\nu \alpha^{b} & \nu\left(1-\alpha^{b}\right) & 1-\nu \\
\nu \alpha^{b} & \nu\left(1-\alpha^{b}\right)-A^{b} & 1-\nu \\
0 & -\epsilon^{b} A^{b} & 1
\end{array}\right]
$$

The characteristic polynomial of $N$ is:

$$
\tilde{P}(p)=-p^{3}+\left[1+\nu-A^{b}\right] p^{2}+\left[A^{b} \nu \alpha^{b}-\nu+A^{b}+\epsilon^{b} A^{b}(\nu-1)\right] p-A^{b} \nu \alpha^{b} .
$$

We determine the location of the roots of $\tilde{P}(p)=0$ by drawing $\tilde{P}(p)$ over $(-\infty,+\infty)$. First, note that $P(0)=-A^{b} \nu^{b} \alpha^{b}<0, P(-\infty)=+\infty$ and $P(+\infty)=-\infty$. Moreover, we have that $P(1)=\epsilon^{b} A^{b}(\nu-1)>0$, which implies that one of the roots (say $\tilde{p}_{1}$ ) lies between 0 and 1 , while another (say $\left.\tilde{p}_{2}\right)$ lies in $(1,+\infty)$. The third root, $\tilde{p}_{3}$, is below -1 if and only if:

$$
P(-1)=2\left(1+\nu^{b}-A^{b}\left(1+\nu \alpha^{b}\right)+\epsilon^{b} A^{b}(1-\nu)<0\right.
$$

When $k^{b}$ is close to $k^{*}$, our assumption throughout, $\nu$ is close to 1 and $A^{b}, \alpha^{b}$ and $\epsilon^{b}$ are close to $A^{*}, \alpha^{*}$ and $\epsilon^{*}$, respectively. At $k^{b}=k^{*}$ the latter inequality becomes:

$$
P(1)=2\left(2-A^{*}\left(1+\alpha^{*}\right)<0\right.
$$

and is thus satisfied under condition (12). This implies that there is a neighborhood of $k^{*}$ such that when $k^{b}$ lies in this neighborhood the dynamics of the bubbly system has exactly one stable root. Then, the dynamics of capital in this neighborhood $\hat{k}_{t+1}=\tilde{p}_{1} \hat{k}_{t}$, which gives (19) in the body of the paper.

\section{Local dynamics of the model with skill heterogeneity}

\section{C1. Bubbleless equilibrium}

The bubbleless equilibrium is given by equations (22), (24) and (25). Defining $R_{t} \equiv 1+r_{t}$ and linearizing (22) around the bubbleless steady states gives:

$$
\hat{R}_{t}=(\alpha-1) \varkappa^{*} \hat{k}_{t}+\beta \varkappa^{*} \hat{\ell}_{t}, \quad \text { with } \varkappa^{*}=\frac{\alpha \Omega k^{* \alpha-1} \ell^{* \beta}}{\alpha \Omega k^{* \alpha-1} \ell^{* \beta}+1-\delta} \in(0,1] .
$$


Linearizing (24) gives:

$$
\hat{\ell}_{t}=-\psi^{*} \hat{R}_{t+1}, \quad \text { with } \psi^{*}=\frac{(1-\alpha) \lambda \theta R^{*}}{\left[(1-\theta) R^{*}+\theta \lambda\right]\left((1-\alpha-\beta) \theta\left(R^{*}-\lambda\right)+\beta R^{*}\right)}>0 .
$$

Finally, linearizing (25) gives:

$$
\hat{k}_{t+1}=\alpha \hat{k}_{t}+\beta \hat{\ell}_{t}
$$

We obtain a two-dimensional system by substituting $\hat{R}_{t}$ (first equation) into the linearized expression for $\hat{\ell}_{t}$ (second equation). In matrix form, we have $\hat{x}_{t+1}=M_{s} \hat{x}_{t}$, where:

$$
M_{s}=\left[\begin{array}{cc}
\alpha & \beta \\
\alpha(1-\alpha) / \beta & 1-\alpha-1 / \beta \psi^{*} \varkappa^{*}
\end{array}\right] .
$$

The characteristic polynomial of $M_{s}$ is:

$$
P_{s}(p)=p^{2}-\left(1-1 / \beta \psi^{*} \varkappa^{*}\right) p-\alpha / \beta \psi^{*} \varkappa^{*},
$$

so that $P_{s}(+\infty)=P_{s}(-\infty)=+\infty, P_{s}(0)=-\alpha / \beta \psi^{*} \varkappa^{*}<0$ and $P_{s}(1)=(1-\alpha) / \beta \psi^{*} \varkappa^{*}>0$. Hence, $P_{s}(p)=0$ has one root, $p_{s 1}$, that belongs to $(0,1)$. The other one is strictly less than -1 if and only if $P_{s}(-1)<0$, that is, if and only if:

$$
(1+\alpha) / \beta \psi^{*} \varkappa^{*}>2 .
$$

Since $\varkappa^{*} \leq 1$, a sufficient condition for the inequality to be satisfied is $(1+\alpha) / \beta \psi^{*}>2$, that is, after rearranging,

$$
\frac{1+\alpha}{1-\alpha}\left[1+\left(\frac{1-\theta}{\theta}\right) \frac{R^{*}}{\lambda}\right]\left(1+\frac{(1-\alpha-\beta) \theta\left(R^{*}-\lambda\right)}{\beta R^{*}}\right)>2 .
$$

This inequality is necessarily satisfied since, with the production function (21), the determinacy condition (12) (our assumption throughout) gives:

$$
\frac{1+\alpha}{1-\alpha}\left[1+\left(\frac{1-\theta}{\theta}\right) \frac{R^{*}}{\lambda}\right]>2
$$

while $(1-\alpha-\beta) \theta\left(R^{*}-\lambda\right) / \beta R^{*}>0$. Thus, in the vicinity of the steady state the bubbleless dynamics has exactly one root inside the unique circle, $p_{s 1}$. This implies that the bubbleless equilibrium exists and is locally unique.

\section{C2. Bubbly equilibrium}

The bubbly equilibrium is given by equations (22), (24), (26) and (27). Linearizing (22) and (24) around the bubbly steady states gives:

$$
\begin{aligned}
& \hat{R}_{t}=(\alpha-1) \varkappa^{b} \hat{k}_{t}+\beta \varkappa^{b} \hat{\ell}_{t}, \text { with } \varkappa^{b}=\frac{\alpha \Omega\left(k^{b}\right)^{\alpha-1} \ell^{b \beta}}{\alpha \Omega\left(k^{b}\right)^{\alpha-1}\left(\ell^{b}\right)^{\beta}+1-\delta} \in(0,1] \text {, and } \\
& \hat{\ell}_{t}=-\psi^{b} \hat{R}_{t+1} \text {, with } \psi^{b}=\frac{(1-\alpha) \lambda \theta R^{b}}{\left[(1-\theta) R^{b}+\theta \lambda\right]\left((1-\alpha-\beta) \theta\left(R^{b}-\lambda\right)+\beta R^{b}\right)}>0 .
\end{aligned}
$$


Second, linearizing equation $(26)$ around $\left(k^{b}, \ell^{b}\right)$ gives:

$$
\hat{k}_{t+1}=\nu_{s} \alpha \hat{k}_{t}+\nu_{s} \beta \hat{\ell}_{t}+\left(1-\nu_{s}\right) \hat{b}_{t}
$$

where $\nu_{s} \equiv(1-\alpha)(n+\delta) / \alpha(1+n)>1$ under inequality (28). Finally, (27) gives:

$$
\hat{b}_{t+1}=\hat{b}_{t}+\hat{R}_{t+1}
$$

The linearized bubbly system is three-dimensional (since $\hat{R}_{t+1}$ can be eliminated from the system). One can thus write the bubbly equilibrium under skill heterogeneity in matrix form as $\left[\begin{array}{lll}\hat{k}_{t+1} & \hat{\ell}_{t+1} & \hat{b}_{t+1}\end{array}\right]^{\prime}=N_{s}\left[\begin{array}{lll}\hat{k}_{t} & \hat{\ell}_{t} & \hat{b}_{t}\end{array}\right]^{\prime}$, with:

$$
N_{s}=\left[\begin{array}{ccc}
\nu_{s} \alpha & \nu_{s} \beta & 1-\nu_{s} \\
(1-\alpha) \nu_{s} \alpha / \beta & (1-\alpha) \nu_{s}-1 / \beta \varkappa^{b} \psi^{b} & (1-\alpha)\left(1-\nu_{s}\right) / \beta \\
0 & -1 / \psi^{b} & 1
\end{array}\right]
$$

The characteristic polynomial of $N_{s}$ is:

$$
\begin{aligned}
\tilde{P}_{s}(p) & =-p_{s}^{3}+\left[1+(1-\alpha) \nu_{s}-\frac{1}{\beta \varkappa^{b} \psi^{b}}+\nu_{s} \alpha\right] p^{2} \\
& +\left[-\left(\frac{1-\alpha}{\beta}\right) \frac{\left(1-\nu_{s}\right)}{\psi^{b}}-(1-\alpha) \nu_{s}+\frac{1}{\beta \varkappa^{b} \psi^{b}}-\nu_{s} \alpha+\frac{\nu_{s} \alpha}{\beta \varkappa^{b} \psi^{b}}\right] p-\frac{\nu_{s} \alpha}{\beta \varkappa^{b} \psi^{b}} .
\end{aligned}
$$

Here again, the location of the roots of $\tilde{P}_{s}(p)=0$ can be found by drawing $\tilde{P}_{s}(p)$ over $(-\infty,+\infty)$. Note that $\tilde{P}_{s}(-\infty)=+\infty, \tilde{P}_{s}(+\infty)=-\infty$, while

$$
\tilde{P}_{s}(0)=-\frac{\nu_{s} \alpha}{\beta \varkappa^{b} \psi^{b}}<0, \quad \tilde{P}_{s}(1)=-\left(\frac{1-\alpha}{\beta}\right) \frac{\left(1-\nu_{s}\right)}{\psi^{b}}>0 .
$$

This establishes the location of the first two roots, $\tilde{p}_{s 1} \in(0,1)$ and $\tilde{p}_{s 2} \in(1,+\infty)$. The third root, $\tilde{p}_{s 3}$, is necessarily negative. A necessary and sufficient condition for $\tilde{p}_{s 3}<-1$ (so that the equilibrium is locally unique) is that $\tilde{P}_{s}(-1)<0$, that is,

$$
1+(1-\alpha) \nu_{s}-\frac{1}{\beta \varkappa^{b} \psi^{b}}+\nu_{s} \alpha+\left(\frac{1-\alpha}{\beta}\right) \frac{\left(1-\nu_{s}\right)}{2 \psi^{b}}-\frac{\nu_{s} \alpha}{\beta \varkappa^{b} \psi^{b}}<0 .
$$

This inequality is true provided that $k^{b}$ is sufficiently close to $k^{*}$ (or, equivalently, provided that $b$ is sufficiently small). Indeed, as $k^{b}$ approaches $k^{*}, \nu_{s}$ and $\psi^{b}$ approach 1 and $\psi^{*}$, respectively, and the right hand side of the latter inequality approaches $2-(1+\alpha) / \beta \varkappa^{*} \psi^{*}$. We know from the local dynamics of the bubbleless equilibrium above that $2-(1+\alpha) / \beta \varkappa^{*} \psi^{*}$ is negative under condition (12).

\section{Proof of Proposition 3}

In steady state, the consumption of unskilled workers is $c_{u}(\theta)=w_{u}[\theta \lambda+(1-\theta)(1+r)]$, where $\left(w_{u}, r\right)=\left(w_{u}^{*}, r^{*}\right)$ or $\left(w_{u}^{b}, r^{b}\right)$, while $c_{u}(\theta)$ is continuous in $\theta$ over [0,1]. The first part of the 
proposition requires us to show that $c_{u}^{b}(1)<c_{u}^{*}(1)$, while $c_{u}^{b}(0)>c_{u}^{*}(0)$ (in case the $c_{u}^{b}(\theta)$-curve crosses the $c_{u}^{*}(\theta)$-curve more than once, $\theta_{u}^{*}$ is the crossing that is closest to $\left.\theta=1\right)$. The first inequality holds if and only if $w_{u}^{b}<w_{u}^{*}$. Using the steady state counter part of (21) and (22) and rearranging, we can rewrite the steady state wage of unskilled workers, $w_{u}$, as follows:

$$
w_{u}=\left(\frac{1-\alpha-\beta}{u}\right) \Omega k^{\alpha} \ell^{\beta}=\left(\frac{1-\alpha-\beta}{\alpha u}\right)(\alpha \Omega)^{\frac{1}{1-\alpha}} \times\left(\frac{\ell^{\beta}}{(r+\delta)^{\alpha}}\right)^{\frac{1}{1-\alpha}},
$$

where $(\ell, r)=\left(\ell^{*}, r^{*}\right)$ or $\left(\ell^{b}, r^{b}\right)$. We have that $r^{b}>r^{*}$ (our condition for the bubbly steady state to exist, assumed throughout), which in turn implies that $\ell^{b}<\ell^{*} \forall \theta \in[0,1]$ (see (24)). Hence $w_{u}^{b}<w_{u}^{*}$, which implies that $c_{u}^{b}(1)<c_{u}^{*}(1)$.

We now need to show that $c_{u}^{b}(0)>c_{u}^{*}(0)$. When $\theta=0, \ell=1$ (see (24) again) and hence

$$
c_{u}(0)=w_{u}(1+r)=\left(\frac{1-\alpha-\beta}{\alpha u}\right)(\alpha \Omega)^{\frac{1}{1-\alpha}} \times \frac{1+r}{(r+\delta)^{\frac{\alpha}{1-\alpha}}} .
$$

Computing the derivative $\partial c_{u}(0) / \partial r$, we find that it is positive whenever $(r+\delta) /(1+r)>$ $\alpha /(1-\alpha)$. This inequality is satisfied at $r=r^{*}$, while $(r+\delta) /(1+r)$ is increasing in $r$; hence $c_{u}(0)$ is increasing in $r$ over $\left[r^{*}, r^{b}\right]$, which implies that $c_{u}^{b}(0)>c_{u}^{*}(0)$.

Let us turn to second part of the proposition, which bears upon the asymptotic consumption level of skilled workers in the vicinity of $\theta_{u}^{*}$. From (23) and the fact that the interest rate paid to a worker does not depend on whether he is skilled or not, we know that

$$
\frac{c^{*}(\theta)}{c_{u}^{*}(\theta)}=\frac{\beta u}{(1-\alpha-\beta) \ell^{*}}<\frac{c^{b}(\theta)}{c_{u}^{b}(\theta)}=\frac{\beta u}{(1-\alpha-\beta) \ell^{b}}, \forall \theta \in[0,1]
$$

By definition, at $\theta=\theta_{u}^{*}$ we have that $c_{u}^{*}(\theta)=c_{u}^{b}(\theta)$, and hence $c^{b}\left(\theta_{u}^{*}\right)>c^{*}\left(\theta_{u}^{*}\right)$. Since both $c^{b}(\theta)$ and $c^{*}(\theta)$ are continuous in $\theta, c^{b}(\theta)>c^{*}(\theta)$ provided that $\theta$ is sufficiently close to $\theta_{u}^{*}$. 